\title{
Graphene and Lithium-Based Battery Electrodes: A Review of Recent Literature
}

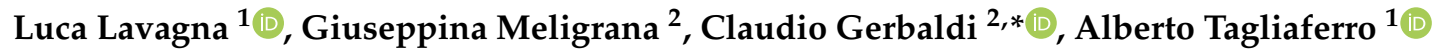 \\ and Mattia Bartoli ${ }^{1, *(\mathbb{C})}$ \\ 1 Department of Applied Science and Technology, C. so Duca degli Abruzzi 24, 10129 Torino, Italy; \\ luca.lavagna@polito.it (L.L.); alberto.tagliaferro@polito.it (A.T.) \\ 2 GAME Lab, Department of Applied Science and Technology, C. so Duca degli Abruzzi 24, \\ 10129 Torino, Italy; giuseppina.meligrana@polito.it \\ * Correspondence: claudio.gerbaldi@polito.it (C.G.); mattia.bartoli@polito.it (M.B.); \\ Tel.: +39-0110904643 (C.G.); +39-0110907348 (M.B.)
}

Received: 30 August 2020; Accepted: 15 September 2020; Published: 17 September 2020

\begin{abstract}
Graphene is a new generation material, which finds potential and practical applications in a vast range of research areas. It has unrivalled characteristics, chiefly in terms of electronic conductivity, mechanical robustness and large surface area, which allow the attainment of outstanding performances in the material science field. Some unneglectable issues, such as the high cost of production at high quality and corresponding scarce availability in large amounts necessary for mass scale distribution, slow down graphene widespread utilization; however, in the last decade both basic academic and applied industrial materials research have achieved remarkable breakthroughs thanks to the implementation of graphene and related 1D derivatives. In this work, after briefly recalling the main characteristics of graphene, we present an extensive overview of the most recent advances in the development of the Li-ion battery anodes granted by the use of neat and engineered graphene and related 1D materials. Being far from totally exhaustive, due to the immense scientific production in the field yearly, we chiefly focus here on the role of graphene in materials modification for performance enhancement in both half and full lithium-based cells and give some insights on related promising perspectives.
\end{abstract}

Keywords: Li-ion battery; electrode material; graphene; reduced graphene oxide; graphene oxide

\section{Introduction}

Nowadays, graphene represents the last frontier in advanced carbon materials [1]. The European Union (EU) research council enforced a strong campaign (EU Graphene Flagship) to promote the fundamental investigation on graphene and related 1D materials, with the aim to become one of the global leaders in terms of research in the field [1]. This immense interest was due to the astonishing properties of this one-atom-thick planar sheet of carbon atoms densely packed into a hexagonal cell. The intrinsic features of graphene and its subsequent variety of applications have paved the way to new opportunities for future devices and systems in many fields of research.

Graphene is the world's strongest material, and thus may be exploited to improve the mechanical robustness of composite materials. Results of recent research works have confirmed that the addition of a very limited quantity of graphene to plastics [2,3], metals [4,5] or other materials allows the resulting composites to become much stronger, or lighter (one may exploit the reduced amount of material to achieve the same strength). Such graphene-enhanced composite materials find practical application in a variety of fields, including aerospace [6], building materials [7], mobile devices [8], etc. Due to its advanced properties in thermal conduction, graphene is also a great material to achieve advanced 
heat-spreading solutions, which include heat sinks or films used for dissipating heat [9]. This finds interesting applications in both microelectronics (e.g., to make LED lighting more efficient and longer lasting) and in larger applications, such as thermal foils for mobile devices. Graphene has a lot of other promising applications, such as anti-corrosion coatings [10] and paints [11], efficient and precise sensors [12], faster and efficient electronics [13], flexible displays, efficient solar panels, faster DNA sequencing [14], and drug delivery [15]. Due to its peculiar structural-morphological characteristics and due to the highest surface-area to volume ratio, graphene holds highly-promising prospects for use in energy storage devices, viz batteries and supercapacitors [16].

Energy storage systems are the new frontiers in energy research. Among all of the available battery systems and, in particular, lithium-based ones are the most representative ones. Lithium-ion batteries (LIBs) are at the core of a strong research interest due to their excellent performances of excellent energy-to-weight ratio, high voltage at open circuit, limited self-discharge rate, no memory effect and long charge/discharge life [17]. Firstly commercialized by Sony in 1990 [18], LIBs rapidly have become the energy storage device of choice in the worldwide market of power supply for portable electronic devices [19]. Nowadays, the best commercial LIBs are able to deliver capacities up to thousands of $\mathrm{mAh}$ at high $2-3 \mathrm{C}$ current rate, with an elevated energy density of up to hundreds of Wh kg-1 $[20,21]$. The international tendency of original equipment manufacturers (OEM) is to move towards solid state systems coupled with advanced electrode materials as a solution for replacing the current liquid electrolyte-based LIBs. The main reason is the necessity to achieve enhanced energy density while employing inherently safer energy storage devices. In particular, based on the "Strategic Energy Technology Plan (SET Plan) Implementation Plan for Action 7 ('Batteries')" [22], for the so-called generation 4a (standard NMC/Si based LIBs with solid-state electrolyte), an energy density $>350 \mathrm{Wh} \mathrm{kg}^{-1}$ and $>1000 \mathrm{Wh} \mathrm{L}^{-1}$ is expected in the very next future, while for generation $4 \mathrm{~b}$ (solid-state Li-metal batteries) an even higher energy density $>400 \mathrm{Wh} \mathrm{kg}^{-1}$ and $>1200 \mathrm{Wh} \mathrm{L}^{-1}$; in addition, fast charge rates above $10 \mathrm{C}$ allowing power density values $>10,000 \mathrm{~W} \mathrm{~kg}^{-1}$ are foreseen as 2030 target.

The rapid technological advancements in the energy storage field have led to a fast-growing interest in the use of graphene and related 1D materials in secondary batteries, as the smart exploitation of the overall potential of graphene can greatly enhance many characteristics of common LIBs and provide improved chemical stability, enhanced electrical conductivity and higher specific capacity output. In this respect, after an initial overview on graphene properties, also focusing on the main achievements and issues, here we extensively review some recent advancements in the use of graphene and related 1D materials as smart additives in the production of advanced lithium battery electrodes, finally highlighting some future ideas and prospects.

\section{Graphene and Graphene Related Materials Properties}

\subsection{Inside Mechanical Properties of Graphene}

"Graphene is the strongest material ever tested"; with this sentence Lee et al. [23] declared the extraordinary properties of this material with an intrinsic tensile strength of $130.5 \mathrm{GPa}$, a Young's modulus of $1 \mathrm{TPa}$, a specific surface area of up to $2630 \mathrm{~m}^{2} \mathrm{~g}^{-1}$ [24], and a thermal conductivity of up to $3000 \mathrm{Wm}^{-1} \mathrm{~K}^{-1}[25,26]$. The impressive mechanical properties are amongst the reasons that make graphene one of the most investigated materials as a reinforcing agent in composites. Its exceptional mechanical properties are due to the stability of the $\mathrm{sp}^{2}$ bonds that forms the hexagonal structure and does not permit a variety of in-plane deformations [27]. The maximum stress was obtained using the equation:

$$
\sigma_{m}^{2 D}=\left(\frac{F E_{2 D}}{4 \pi R}\right)^{1 / 2}
$$

where $\mathrm{E}_{2 D}$ is the second order elastic stiffness, $R$ is the tip radius and $F$ is the applied force. However, the breaking strength of $55 \mathrm{~N} \mathrm{~m}^{-1}$, which can be obtained by this equation, cannot be considered 
accurate, because the model used ignores non-linear behavior. Both from experimental works and from simulations, the breaking force was almost identical. The elastic stiffness value for the second order is equal to $E_{2 D}=340 \pm 50 \mathrm{~N} \mathrm{~m}^{-1}$. Assuming an effective thickness of $0.335 \mathrm{~nm}$, this value corresponds to a Young's modulus of E $=1.0 \pm 0.1 \mathrm{TPa}$ [23], as summarized in Figure 1.
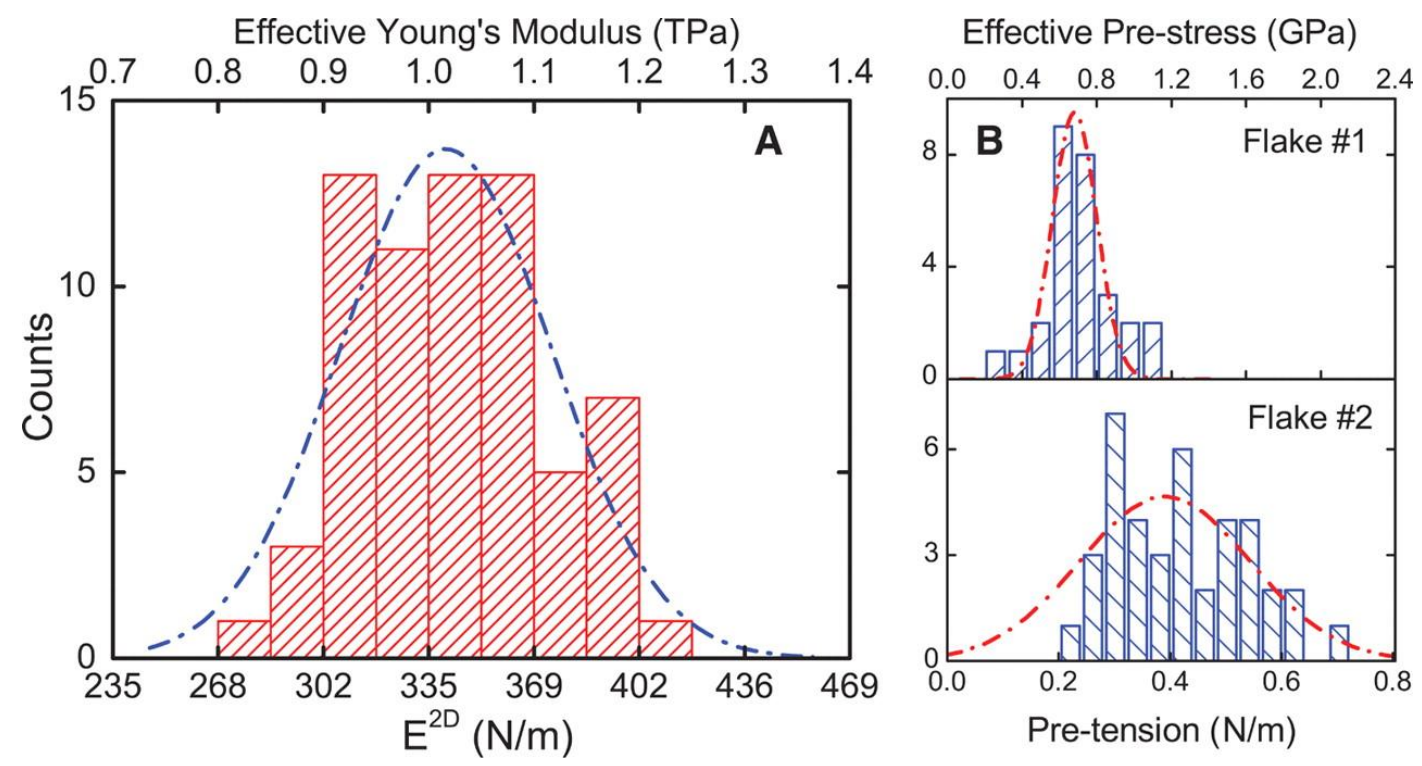

Figure 1. Elastic response test results. (A) Histogram of elastic stiffness. (B) Histogram of film pretensions. Dashed lines in both plots represent Gaussian fits to data. The effective Young's modulus and prestress were obtained by dividing the graphite interlayer spacing Reproduced, adapted and reprinted with permission from Reference [23].

Zandiatashbar et al. [28] have studied the effect of defects on the intrinsic strength and stiffness of graphene. Interestingly, both properties in graphene are maintained also with a defective structure. The breaking strength, in fact, is only $14 \%$ lower than that of pristine graphene dropping significantly.

The toughness of graphene is similar to most commercially available fibers $[29,30]$ and carbon membranes used for gas filtration [31] and depends upon their weakest link where failure initiates [32]. Furthermore, the attempts to scale up the production of large graphene sheets lead to the formation of a material that contains numerous defects, and thus possesses inferior mechanical properties [27]. The outstanding mechanical properties of graphene allow for its use for the fabrication of highly flexible self-standing electrodes $[33,34]$.

\subsection{The Electrical Properties of Graphene}

Graphene elementary cell is composed by three $\sigma$ bonds, the $\mathrm{p}$ orbitals are perpendicular to the $\mathrm{sp}^{2}$ plane and this allow the delocalized $\pi$ bond. Thus the electrons presents in the $\pi$ bond are free to move in all the plane [35-37]. As consequence, graphene has extremely high electronic conductivity, and it exhibits semi-integer quantum Hall effect, bipolar electric field effect, superconductivity, high carrier rate, and excellent electrical properties [26]. At room temperature, its carrier mobility can reach $15,000 \mathrm{~cm}^{2} \mathrm{~V}^{-1} \mathrm{~s}^{-1}$ thousands of times higher than carbon black that can reach $5.4 \mathrm{~cm}^{2} \mathrm{~V}^{-1} \mathrm{~s}^{-1}$ [38]. The electrons and holes are free to move as free carriers, as summarized in Figure 2. Altogether, they create an electrical conduction under the action of an external electric field to form macroscopic currents. 

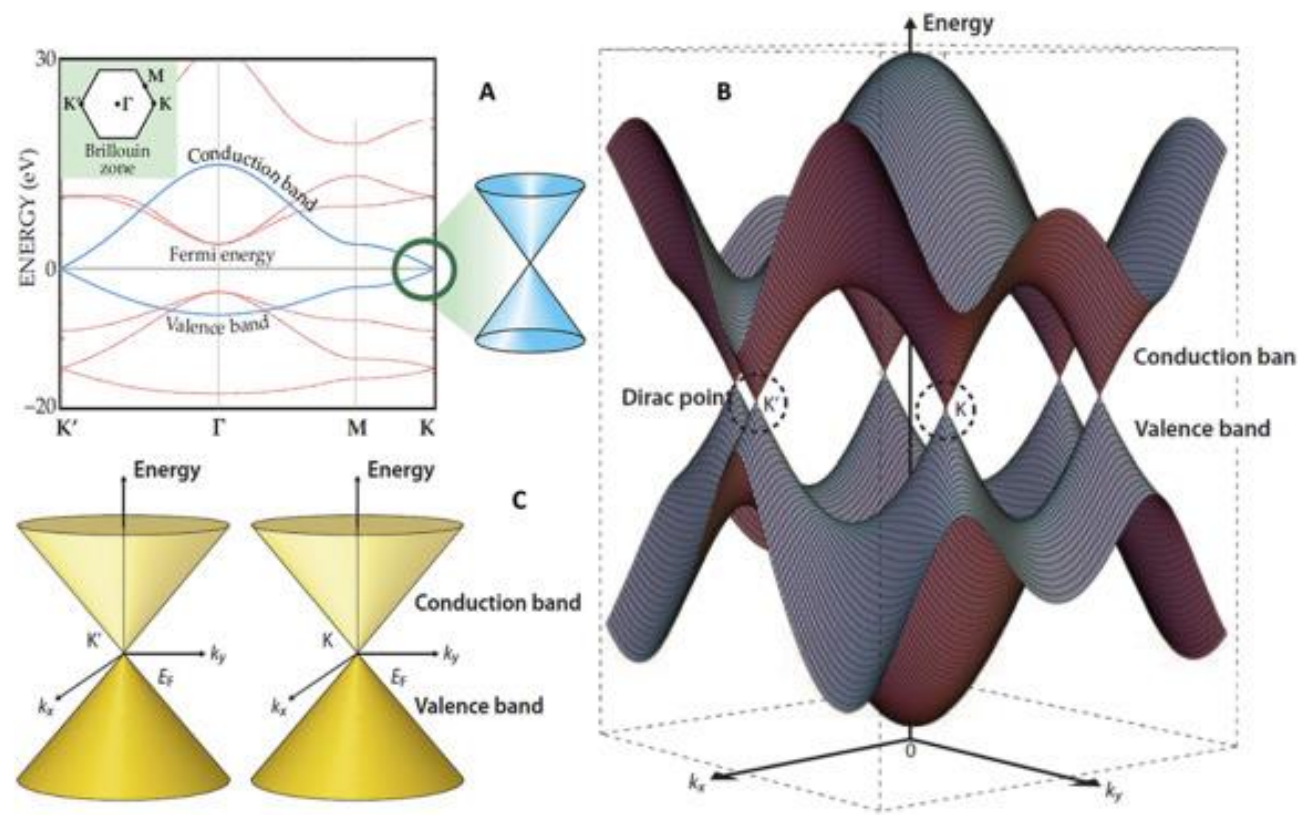

Figure 2. Band structure near the Fermi level of graphene. (A) 2D schematic diagram [39], (B) 3D schematic diagram, and (C) Dirac cone of $K$ and $K^{\prime}$, which corresponds to the Fermi level of (B). Reproduced, adapted and reprinted with permission from Reference [40].

Most of the experimental research on graphene focuses on the investigation of its electronic properties. The Hall effect of graphene is extensively studied. Thinnest samples have a pronounced Hall effect, whereas multi layered samples present much weaker gate dependence due to screening of the electric field by the other layers. With a high magnetic field and at low temperatures, the quantum Hall effect for both electrons and holes can be observed [41,42]. The graphene quantum Hall effect is slightly different from conventional quantum Hall effect. Actually, the plateaus occur at half integers of $4 \mathrm{e}^{2} / \mathrm{h}$ rather than the typical $4 \mathrm{e}^{2} / \mathrm{h}$.

Regrettably, graphene does not have band gap and, so the resistivity changes are small. Hence, graphene as a transistor by its very nature is plagued by a low on/off ratio. To overcome this problem, it is possible to carve graphene into narrow ribbons. By shrinking, in the ribbon the momentum of charge carriers in the transverse direction becomes quantized, which results in the opening of a band gap, determined by the width of the ribbon. The studies about opening of a band gap in graphene ribbons are addressed both in wide ribbon devices lithographically patterned from large graphene flakes [43] and in narrow chemically synthesized graphene ribbons [44].

\subsection{Graphene Related Materials: An Overview}

Graphene oxide (GO) is a graphene derivative rich in oxygens functional groups. It has epoxide and hydroxyl groups on its basal lattice, and aldehyde, carboxylic and ketone groups on its layer edge. Hence, GO is a material structurally rich in oxygen, carbon and hydrogen. Due to the fact that different methods are used to synthesize GO, its composition and non-stoichiometric structure are highly based on the production details [45]. Consequently, numerous studies has proposed several structures of GO, namely the Hofmann, Ruess, Scholz-Boehm, Nakajima-Matsuo, Lerf-Klinowski and Szabo models [46], as shown in Figure 3b-g. 


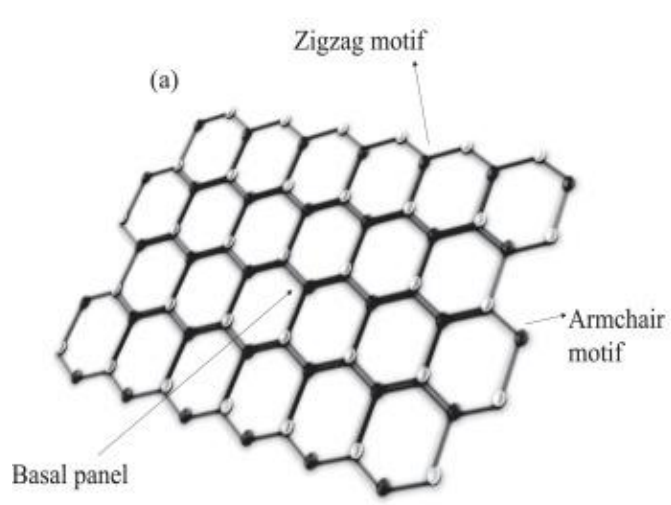

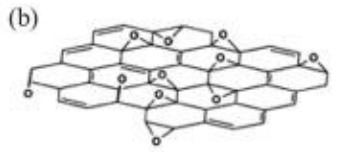
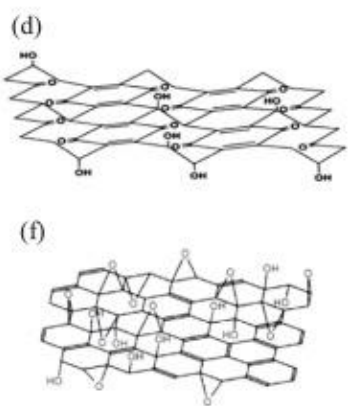

(c)

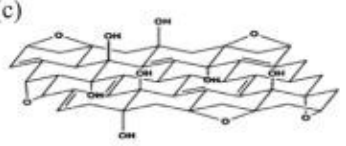

(e)

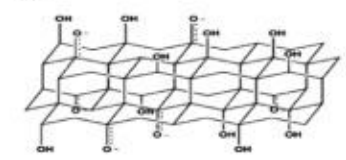

(g)

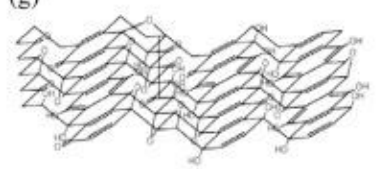

Figure 3. Structures of pristine graphene (a) and its GO derivatives based on Hofmann (b), Ruess (c), Scholz-Boehm (d), Nakajima-Matsuo (e), Lerf-Klinowski (f) and Szabo (g) models. Reproduced, adapted and reprinted with permission from Reference [47].

The Lerf-Klinowski molecular structure is widely accepted as the more adequate to describe the real GO following an exhaustive set of experimental evidences from solid-state nuclear magnetic resonance and X-ray diffraction [48]. The presence of defects, structural disorder, cracks, wrinkles, fragmentation, impurities and other structural attributes are principally due to the oxidation process. This, obviously, will affect the electronic, optical and adsorption properties of GO. Through a reduction process is possible to produce another graphene derivative known as reduced graphene oxide (rGO). The transformation from GO to rGO can be obtained through chemical or physical reaction. In the process, the oxygenated functional groups in the GO are eliminated to form $\mathrm{rGO}$ with a carbon to oxygen $(\mathrm{C} / \mathrm{O})$ ratio in the range of 8:1 to 246:1 [49]. Being good absorbers, graphene, GO and rGO are used as precursors for the preparation of materials that can be used for the decontamination of water from heavy metals [50].

\subsection{Graphene and Related Materials: Productive Processes}

The synthesis of graphene can be performed by two main approaches: "destruction" and "construction" methods [51,52]. The destruction methods consist of isolation and delamination of the layers of graphite into single-, bi- and few-layered graphene. These methods usually tend to use a larger precursor like graphite or other carbon-based materials and destroy them to form nano-sized graphene. Generally, the "destruction" methods are highly industrially up-scalable and produce high quality graphene. Nevertheless, some issues remain like the difficulties in forming products with consistent properties, low yield and reliability on the finite graphite precursor-the "construction" methods. In addition to graphite, other carbon sources are also used for the synthesis of graphene and its derivatives. With these methods, graphene is constructed from atomic-sized precursors. While these methods make it possible to produce nearly defect-free materials, production costs are high and the equipment required is often sophisticated.

Generally, both the bottom-up and the top-down methodologies are repetition of the four classical methods that are classified in function of the methodology, namely micromechanical cleavage, liquid-phase mechanical exfoliation, chemical cleavage and exfoliation, and chemical vapor deposition (CVD). A brief description of each method is given below.

\subsubsection{Micromechanical Cleavage}

In 2004, the Nobel prize winner Novoselov and coworkers published a research article detailing electronic measurements made on single- and few-layered graphene [53]. They obtained graphene by 
successively removing layers of graphite from a pencil using an adhesive tape. This technique was called micromechanical cleavage.

However, the method was not new, the real novelty of this methodology was to realize that the thin flakes obtained could be further cut into subsequently thinner samples. With this breakthrough, they were able to perform experiments that demonstrated the electronic structure of the graphene monolayer, thus allowing the observation of the anomalous quantum Hall effect, confirming the Dirac-fermionic behavior of charge carriers in graphene.

\subsubsection{Liquid-Phase Mechanical Exfoliation}

One of the main problems with carbon is that it is insoluble in the most common polar solvents. This has always created major problems in the study, for example, of carbon nanotubes, since the tubes tend to aggregate in bundles and cannot be solvated by most commonly available solvents. The problem was solved by pursuing two strategies. In the first, the nanotubes are mixed with a solution of water and surfactant and subsequently sonicated. The hydrophobic part of the surfactant solvates the surface of the nanotube, while the hydrophilic part stabilizes the dispersion in the solution. In the second strategy, the nanotubes are sonicated directly without the use of the surfactant. The solvent used, in this case, must have a surface tension close to the surface energy of the carbonaceous material. This reduces the energy gap between the nanotubes and the solvent by allowing the nanotubes to separate from their bundles and allows a fraction of the weakly dispersed nanotubes to persist in solution. To obtain exfoliated graphene in large quantities, the same methods explained above can be used. The sonication of graphite powder in $\mathrm{N}$-methylpyrrolidone and subsequent centrifugation creates a dispersion of non-exfoliated graphite plates with few-layered graphene concentrations below $1 \%$ by weight. This dispersion has shown remarkable stability over long periods [54]. Surfactant-assisted graphene exfoliation is another well-established technique, with many surfactants being employed [55-60]. The choice of the surfactant and the effect of physicochemical parameters (e.g., critical micellar concertation, chemical functionalities) were studied by Wang et al. [61]. The authors clearly showed the different behavior between ionic and non-ionic surfactants due to the different colloidal phases assembled.

\subsubsection{Chemical Cleavage and Exfoliation}

The chemical reactivity of graphite was first studied in 1859 by Benjamin Brodie during some attempts to measure the atomic weight of carbon [62]. In his experiment, graphite can be oxidized using a mixture of nitric acid and potassium chlorate for several days. At the end of this experiments, he obtained "a substance having a light-yellow color, consisting of minute transparent and brilliant plates." He went on evaluating many properties of what he called graphitic acid, nowadays known as GO. In 1898, Staudenmaier described another method based on the use of an acidic solution of $\mathrm{KClO}_{3}$ for the production of graphitic acid [63]. Nearly a half century later, the Hummers and Offeman method was used to obtain GO in a "significantly" safer way of synthesis. In this method, GO is obtained from graphite using a solution of sodium nitrate, sulfuric acid, and potassium permanganate [64]. This method is mostly used to produce graphite oxide in the laboratory. These three methods represent the early history of GO, but they are still used leading to different kind of GO Poh et al. [65] deeply described the different properties of rGO produced from GO obtained by using the methods above mentioned enlightening the effect of different oxygen-containing functionalities on the final properties of rGO itself. This study proved that the one proposed by Hummers is the most effective method for the production electroactive materials.

Recently, more sustainable methods are developed to overcome the use of heavy acids and sodium that is an impurity in the graphite lattice and it is difficult to remove from GO after its production [66]. 


\subsubsection{Chemical Vapor Deposition}

The synthesis of graphene using thermal chemical vapor deposition is a recent technique. The first studies date back to 2006 [60] when camphor was used as a precursor to synthesize graphene on Ni sheets. This study has opened up a new processing path for graphene synthesis, however many problems remain to be solved. Currently there is still a lack of control over the number of layers and the reduction of the number of folds of the graphite surface. Despite these problems, CVD allows good reproducibility of good quality graphene. Furthermore, this technique is quite versatile and can be applied to different substrates of different sizes. In fact, new paths are being developed over time for the application of graphene in photovoltaic and flexible electronics. We will soon see the possibility of growing graphene even on wafer-sized substrates, thus increasing the use of graphene in real applications [61].

\subsection{Consideration on Cost-Effectiveness of Graphene and Related Materials}

In a very optimistic report, Segal [67] dreamed that the world was ready for the industrial-scale production of graphene, but after a decade, single-layer graphene is still sold at GBP $200 \mathrm{~cm}^{-2}$, while graphene oxide costs GBP $100,000 \mathrm{~kg}^{-1}[68,69]$.

Undoubtedly, top-down synthetic routes have a lower cost than bottom-up ones. As for the overall cost evaluation of the synthesis pathways, chemical reagents that are used (e.g., $\mathrm{NaNO}_{3}, \mathrm{H}_{3} \mathrm{PO}_{4}$, etc.) comprise both synthesis costs and the purification costs of graphene and its waste water due to the presence of soluble ions, such as $\mathrm{NO}_{3}{ }^{-}$. Currently, more environmentally friendly and low-cost routes for the production of GO have also been reported [66], although still at the experimental stage and without an industrial up-scale [70].

Considering the thermal production of rGO through reduction of graphene oxide, an average temperature of at least $300{ }^{\circ} \mathrm{C}$ is necessary, the use of vacuum is much cheaper than the use of reducing gases (such as $\mathrm{N}_{2}$ or Ar) [34]. On the other hand, other techniques are also used to produce rGO such as "wet" chemical reduction. However, this requires use of reagents $(\mathrm{HCl})$, heat and further purification of rGO from heteroatomic species [71].

A rigorous comparison of costs between literature-based synthesis routes (top-down or bottom-up) could be very complex. In particular, the production cost of graphene and related materials depends on the type of raw graphite used. As an example, different sizes/meshes of graphite require different treatments/conditions for complete oxidation (reduction and exfoliation). Raw graphite with large flake size is cheap compared to the one which is mostly used in the majority of studies, which generally has smaller dimensions.

\section{Graphene and Graphene Related Materials in Secondary Batteries}

Lithium-ion batteries are made of cells, connected in series or parallel, which in their typical configuration contain lithium insertion/intercalation compounds as active materials at the electrodes [72]. The advantageous characteristics of LIBs allowed them to rapidly become the secondary batteries of choice in recent years; actually, they are now largely employed in smartphones, notebooks and other portable/wearable electronic devices, with a rapid intrusion in the electric transportation sector and large-scale storage from renewables. In a standard LIB configuration, both electrodes have a structure able to store lithium ions. Differently from the traditional redox galvanic reaction, the chemistry of rechargeable (secondary) Li-ion cells is based on a "intercalation/de-intercalation" mechanism (to intercalate $=$ process of inserting a substance between the graphene layers of graphite [73]). Other mechanisms not exactly involving intercalation are defined as "insertion/de-insertion" processes. In general, "intercalation" is chiefly employed for host substances having a layered structure (e.g., graphite, $\mathrm{TiS}_{2}, \mathrm{MoS}_{2}$ or $\mathrm{LiCoO}_{2}$ ); more generally, "insertion" is used for those materials having three-dimensional framework with cavities connected by narrow pores/channels. LIB active materials must be electronic as well as ionic conductors, which allows the proper battery operation; actually, 
low electronic conduction or limited $\mathrm{Li}^{+}$ion motion negatively affect the flow of current through the cell and, as a result, the power output of the device.

In the processes of charge and discharge, lithium ions move through the electrolytes across the separator and are reversibly exchanged between the cathode and the anode. The cathode generally is composed by lithiated transition metal oxides with a layered structure, while the anode is typically made of graphitic carbon. Upon charge, lithium ions are released from the cathode, with relative oxidation of the active material; they move through the electrolyte and are intercalated in the layered active material structure at the anode, which gets reduced. The compensating electrons concurrently move through the external circuit and are accepted by the host to balance the reaction. Upon discharge the reverse process occurs, as summarized in the following reactions Scheme 1.

\section{Scheme 1}

\section{Cathode}

Anode

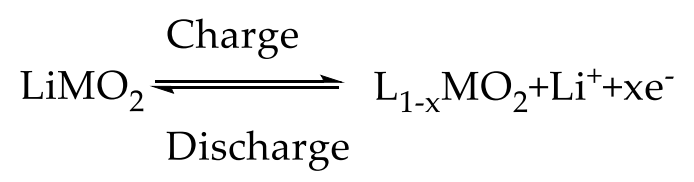

$\mathrm{C}+\mathrm{xLi}^{+}+\mathrm{xe}^{-} \underset{\text { Discharge }}{\rightleftharpoons} \mathrm{Li}_{\mathrm{x}} \mathrm{C}$

Scheme 1. Reversible reaction pathways occurring during charge/discharge process of LIBbatteries.

The above detailed process is reversible, with $\mathrm{Li}^{+}$ions that travel back and forth between the two electrodes upon charge and discharge. This has given rise to the names "rocking chair" [74], "swing" or "shuttlecock" [75] to describe the Li-ion cells.

Electrode materials in LIBs have a series of drawbacks that often limit their practical use depending on the application. Actually, most often carbonaceous materials demonstrate good cycling performance, but limited initial Coulombic efficiency; and rate capability; similarly, silicon and conversion oxides demonstrate enhanced specific capacity, and operation at high current regimes, but highly irreversible capacity loss upon initial cycling. Inventing and properly developing novel active electrode materials with advanced characteristics is amongst the possible solutions to these issues. Graphene, the "wonder material" due to the myriad of astonishing attributes it holds, is considered the suitable electrode alternative also for application in batteries, chiefly due to its chemical stability and high electrical conductivity. The use of graphene as carbon source for the realization of LIB is a widely investigated field of research nowadays, with thousands of new papers every year. For sure, its widespread application is somewhat restricted by the limited sustainability in terms of large-scale production and handling. However, conventional battery electrode materials and prospective ones are significantly enhanced in terms of cycling performances by the use of graphene on lab scale. Actually, the resulting electrode can be lighter, thus more suitable for higher energy and power densities, as well as more durable due to the extended battery life, often affected by the relatively high amount of carbon added to the active materials in the electrodes to allow sufficient electronic conductivity. Graphene may enhance the energy density and many other battery attributes in various ways when included as an additive to the battery electrodes, chiefly by capitalizing on its high electronic conductivity and 
large surface area, which allow achieving morphological optimization structural stability and, in turn, greater performances.

The electrode, most chiefly, anode materials based on graphene presented in this review have shown outstanding performances. A non-exhaustive list of the most recent and representative ones, to our knowledge, is summarized in Table 1 and will be briefly detailed and discussed in the following paragraphs.

Table 1. Overview of the most representative anodes of lithium-based batteries based on graphene reported in the literature so far.

\begin{tabular}{|c|c|c|}
\hline Electrode Material & $\begin{array}{c}\text { Capacity } \\
{\left[\mathrm{mAhg}^{-1}\right]}\end{array}$ & Reference \\
\hline Graphene watery slurry & 1279 & [76] \\
\hline Multilayers graphene from anthracite & 404 & [77] \\
\hline Hierarchical graphene $^{\text {a }}$ & 1178 & [78] \\
\hline Graphene foam from metal template approach ${ }^{a}$ & 844 & [79] \\
\hline Graphene foam from anthracite & 770 & {$[80]$} \\
\hline Channeled few layer graphene & 142 & [81] \\
\hline Hard carbon/graphene hybrid & 623 & [82] \\
\hline Nitrogen doped graphene & 907 & [83] \\
\hline Nitrogen doped graphene through magnesiothermic reduction of melamine & 1753 & [84] \\
\hline Phosphorene-graphene hybrid & 974 & [85] \\
\hline 3D-structured nitrogen doped GO & 830 & {$[86]$} \\
\hline Nitrogen doped rGO & 409 & [87] \\
\hline $\mathrm{Mn}_{3} \mathrm{O}_{4}$ doped graphene & 474 & {$[88]$} \\
\hline $\mathrm{Mn}_{3} \mathrm{O}_{4}$ nanotubes doped graphene & 770 & {$[89]$} \\
\hline $\mathrm{MnO} / \mathrm{Mn}_{3} \mathrm{O}_{4} /$ nitrogen doped graphene hybrid & 365 & [90] \\
\hline Graphene tailored with carbon coated $\mathrm{ZnO}$ nanoparticles & 736 & [91] \\
\hline GO tailored with $\mathrm{MnO}_{2}$ nanotubes & 1290 & {$[92]$} \\
\hline Graphene tailored with $\mathrm{Fe}_{3} \mathrm{O}_{4}$ nanoparticles & 721 & [93] \\
\hline Graphene foam tailored with porous $\mathrm{Fe}_{2} \mathrm{O}_{3} / \mathrm{Fe}_{3} \mathrm{O}_{4}$ & 1210 & [34] \\
\hline $\mathrm{Fe}_{3} \mathrm{O}_{4}$-pillared onto $\mathrm{SiOx}$ microsphere and wrapped by graphene & 833 & {$[94]$} \\
\hline Carbon encapsulated $\mathrm{Fe}_{3} \mathrm{O}_{4}$ doped rGO & 844 & [95] \\
\hline Iron phosphide/rGO & 950 & [96] \\
\hline Cobalt nanoparticles tailored nitrogen doped graphene & 1009 & [97] \\
\hline $\mathrm{CoO}$ tailored rGO & 1167 & [98] \\
\hline $\mathrm{Ni} / \mathrm{Ni}_{3} \mathrm{~S}_{2}$ doped GO & 742 & [99] \\
\hline Copper oxalate/graphene composite & 1043 & {$[100]$} \\
\hline $\mathrm{TiO}_{2} / \mathrm{TiN} /$ graphene & 221 & [101] \\
\hline Graphene decorated with $\mathrm{NaTi}_{2}\left(\mathrm{PO}_{4}\right)_{3} \mathrm{~b}$ & 108 & {$[102]$} \\
\hline rGO tailored with $\mathrm{TiO}_{2}$ nanorods & 354 & [103] \\
\hline Sn nanoparticles supported onto graphene & 584 & {$[104]$} \\
\hline $\mathrm{SnO}_{2} /$ graphene aerogel & 620 & {$[105]$} \\
\hline rGO tailored with $\mathrm{SnO}_{\mathrm{x}}$ & 833 & [106] \\
\hline Graphene tailored with SnS & 790 & {$[107]$} \\
\hline Nano silicon supported onto soft carbon embedded in graphene & 2600 & [108] \\
\hline Silicon/graphene hybrid & 1298 & [109] \\
\hline Graphene tailored with $\mathrm{Co} / \mathrm{ZnO}$ & 1494 & {$[110]$} \\
\hline Al-MOF/graphene composite & 400 & [111] \\
\hline
\end{tabular}

a Lithium-sulfur batteries: graphene and graphene related materials were used for enhancing cathode performances,

${ }^{\mathrm{b}}$ LIBs in aqueous solvent. 


\subsection{Pristine Graphene and Related Materials}

The possibility of fabrication of safe and powerful LIBs using costly, yet simple approaches such as liquid-phase exfoliation [112] was explored by Yong-Jian et al. [76]. The authors used a mechanical and ultrasonic dispersion approach combined with several dispersants (i.e., poly (vinyl pyrrolidone), sodium lignin sulfonate, sodium carboxymethylcellulose) for the production of a graphene-based anode slurry. This system showed initial specific capacity values of capacity of 1279/1724 mAh g-1 upon charge/discharge and a Coulombic efficiency up to $74 \%$ at a constant current of $100 \mathrm{~mA} \mathrm{~g}^{-1}$ with associate corresponding capacity retention of the cell of $84 \%$ after 100 cycles up to $200 \mathrm{~mA} \mathrm{~g}^{-1}$.

Another interesting approach is represented by the use of 3D graphene structures [113]. Wang et al. [78] used a hierarchical porous carbon black/graphene hybrid designed as sulfur host for lithium-sulfur batteries achieving a specific capacity of $1178 \mathrm{mAh} \mathrm{g}^{-1}$ after 70 cycles at $200 \mathrm{~mA} \mathrm{~g}^{-1}$ with a retention of $80 \%$ after 600 cycles.

Lu et al. [79] produced a 3D micron-porous graphene foam used as lightweight binder-free current collector for sulfur cathodes of lithium-sulfur batteries. The authors produced this innovative material by using a porous metal template for CVD growth of graphene layers. After metal etching, the micron-sized porous structures showed both tubular and nontubular pores with average sizes ranging from nanometers to several microns. After sulfur loading $\left(2.5 \mathrm{mg} \mathrm{cm}^{-2}\right)$, the material exhibited an ultrahigh initial capacity up to $844 \mathrm{mAh} \mathrm{g}^{-1}$ with a retention of around $50 \%$ after 50 cycles at $0.1 \mathrm{C}$ ("battery people" use the C-rate to indicate the rate at which a battery is being charged or discharged, viz the specific capacity of a LIB is normally rated at $1 \mathrm{C}$. A C-rate of $1 \mathrm{C}$ means a one-hour discharge to deliver full capacity, which in turn means that a fully-charged battery rated at $1 \mathrm{Ah}$ is able to provide $1 \mathrm{~A}$ for $1 \mathrm{~h} ; 0.5 \mathrm{C}$ or $\mathrm{C} / 2$ means a discharge of $2 \mathrm{~h}$, while $0.2 \mathrm{C}$ or $\mathrm{C} / 5$ a discharge of $5 \mathrm{~h}$, etc.). Graphene foams could be also produced by conversion of anthracite [114] as reported by Xing et al. [80]. Authors described a cost effective and environmentally friendly strategy for the preparation of porous graphene through graphitization coupled with liquid oxidation and rapid thermal reduction of anthracite. The 3D porous graphene showed microstructure made by nanosheets with multiscale hierarchical porous structure and a specific surface area of up to $640 \mathrm{~m}^{2} \mathrm{~g}^{-1}$. The large pore volume together with massively structural defects and nanopores provided the active sites for the storage of lithium ions offering attractive pathways for the fast transportation of both lithium ions and electrons. When used as anode this materials showed a high reversible capacity of $770 \mathrm{mAh} \mathrm{g}^{-1}$ at current density of $0.1 \mathrm{C}$ with remarkably capacities of $274 \mathrm{mAh} \mathrm{g}^{-1}$ and $224 \mathrm{mAh} \mathrm{g}^{-1}$ at high current densities of 10 and $20 \mathrm{C}$. Additionally, the authors claimed a superior capacity retention up to $98 \%$ of the initial reversible capacity retention after 110 cycles.

Zhou et al. [81] developed millimetric sized few-layered graphene sheets with aligned channels having fast lithium-ion charging kinetics. The authors reported a self-catalytic bottom-up route using L-glutamic acid and iron chloride as starting materials for the fabrication of the millimeter-sized graphene sheets through pyrolysis mediated by in-situ generated iron nanoparticles. The produced materials were composed of a few graphene sheets with aligned channels having an average diameter up to $85 \mathrm{~nm}$. These materials were used as anodes in LIBs, and showed good cycling performance, with specific capacities up to $142 \mathrm{~mA} \mathrm{~h} \mathrm{~g}^{-1}$ at $2 \mathrm{~A} \mathrm{~g}^{-1}$ and high capacity retention of $93 \%$ at $2 \mathrm{Ag}^{-1}$ after 1200 cycles. The authors enlightened that the storage of lithium ions in terms of both diffusion and capacitive behavior was accelerated in the channel thanks to improved electron transfer and shortened lithium ions transport pathway.

Zhong et al. [77] converted anthracite and semi-coke into multilayer graphene spheres using nickel as catalyst at relatively low temperature. The related anode materials for LIBs showed good reversible capacity of $401 \mathrm{mAh} \mathrm{g}^{-1}$ at $0.1 \mathrm{Ag}^{-1}$ as clearly evidenced from Figure 4. 
(a)

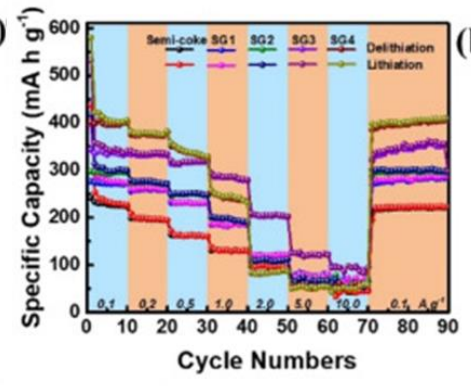

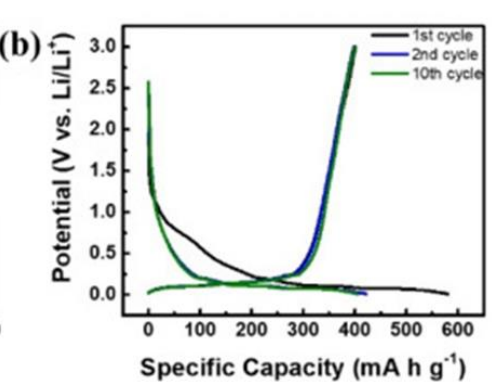

Figure 4. (a) Galvanostatic lithiation/delithiation curves, (b) Lithiation/delithiation voltage profiles and (c) cyclic voltammetry curves of semi-coke derived graphene anode measured at a scanning rate of $0.5 \mathrm{mV} \mathrm{s}^{-1}$. Reproduced, adapted and reprinted with permission from Reference [77].

Even if the materials are far from the astonishing performances of a few graphene layers, the authors reported an easily scalable production route for graphene, which is a remarkable achievement. Additionally, Yan et al. [115] converted anthracite in the presence of molten iron for the production of multilayered graphene sheets used as anode for lithium ion batteries achieving reversible capacity close to $400 \mathrm{mAh} \mathrm{g}^{-1}$.

Li et al. [82] combined a hard carbon from pyrolysis of rapeseed shuck with graphene producing a hybrid sandwich-like porous material. The advantages of highly ordered graphene layers were represented by the conductive multi-dimensional paths for fast electronic transport able to supply sufficient electrons for redox reactions, while concurrently providing enhanced mechanical support. The highly defected and porous hard carbon provided more adsorption sites for lithium storage. This material reached a capacity of $623 \mathrm{mAh} \mathrm{g}^{-1}$ when cycled at a current density of $100 \mathrm{~mA} \mathrm{~g}^{-1}$ after 500 cycles, exhibiting a superior rate performance with 381 and $308 \mathrm{mAh} \mathrm{g}^{-1}$ even at very high current regimes of 2000 and $5000 \mathrm{~mA} \mathrm{~g}^{-1}$, respectively.

\subsection{Doped Graphene and Related Materials}

As reported by many authors, defects in the graphene sheet could provide additional pathways for the lithium ions to attach to the anode substrate. This feature could be the solution of the great challenge of developing LIBs which can concurrently provide high power and energy density outputs at fast charge and discharge rates from several minutes down to seconds. One of the most consolidate process for the introduction of defects in the graphene structure is represented by the doping with nitrogen atoms that reduce the carbon-lithium interaction energy.

Zhang et al. [83] produced a bidimensional hierarchical structure of ultra-highly nitrogen-doped porous graphene nanosheets used as high-efficiency lithium-ion battery anodes. The authors used GO mixed with 2-methyimidazole and poly (vinyl pyrrolidone) as nitrogen precursor pyrolyzing them for the production of nitrogen doped graphene. This material provided a high capacity of up to $907 \mathrm{mAh} \mathrm{g}^{-1}$ after 100 cycles at $0.5 \mathrm{~A} \mathrm{~g}^{-1}$ and an average capacity of up to $378.2 \mathrm{mAh} \mathrm{g}^{-1}$ after over 1000 cycles at high $5 \mathrm{~A} \mathrm{~g}^{-1}$ current regime. Exploiting the remarkable mechanical properties of graphene, Zhao et al. [116] produced a self-standing nitrogen doped porous carbon-graphene coated cable. The authors used the graphene as self-standing host for both the sulfur cathode and lithium anode, producing a full cell able to deliver of up to $525 \mathrm{mAh} \mathrm{g}^{-1}$ with a high capacity retention of $98 \%$ after 100 cycles at $0.5 \mathrm{C}$. Furthermore, in this research the use of additional additives such as urea and cellulose fibers activation was used to increase the level of nitrogen doping up to 7.58 atom $\%$ with resulting improvements of electrocatalytic polysulfide redox kinetics and lithium dendrite inhibition.

An innovative approach for production of nitrogen self-doped graphene nanosheets was reported recently by Wan et al. [84]. The authors described a new strategy based on the magnesiothermic reduction of melamine producing a graphene material that, as an LIB anode, exhibited a reversible specific capacity of $1753 \mathrm{mAh} \mathrm{g}^{-1}$ at $0.1 \mathrm{~A} \mathrm{~g}^{-1}$ after 200 cycles. The reversible capacity was well retained 
at $1322 \mathrm{mAh} \mathrm{g}^{-1}$ after 500 cycles at $2 \mathrm{~A} \mathrm{~g}^{-1}$ and was positively affected by the increment of process temperature as shown in Figure 5.

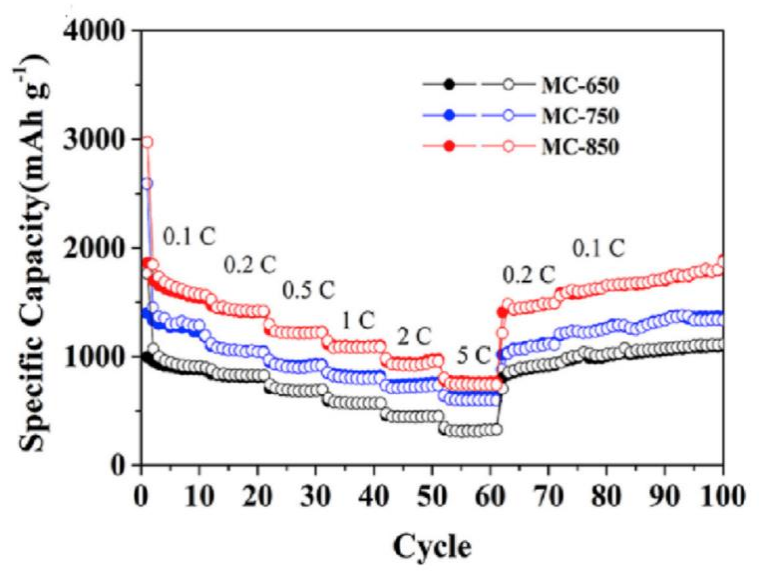

Figure 5. Cyclic performance of self-doped graphene nanosheets produced through magnesiothermic reduction of melamine at $650^{\circ} \mathrm{C}$ (black curve), $750^{\circ} \mathrm{C}$ (blue curve) and $850^{\circ} \mathrm{C}$ (red curve). Reproduced, adapted and reprinted with permission from Reference [84].

Hybrid graphene materials gained a lot of interest, and a combination of graphene with phosphorene monolayers as an anode material for high-performance lithium-ion batteries was investigated for the first time by Javadian et al. [85]. This preliminary study was limited to only computational approaches and estimated a theoretical capacity for a monolayer phosphorene of $865 \mathrm{mAh} \mathrm{g}^{-1}$ while after the combination with graphene it reached of $974 \mathrm{mAh} \mathrm{g}^{-1}$.

Ershadi et al. [86] employed an efficient and straightforward synthesis method for the functionalization and stitching of GO sheets with ethylenediamine producing a 3D-structured nitrogen doped GO, as illustrated in Figure 6. The 3D-structured nitrogen doped GO exhibited a layered structure resembling graphite, with an enhanced d-spacing of $0.373 \mathrm{~nm}$ showing that the porous channels may facilitate the efficient transport of lithium ions through the electrolyte-filled channels. Upon first discharge and charge, the lab-scale cell showed specific capacities of 830 and $664 \mathrm{mAh} \mathrm{g}^{-1}$, respectively, at the current density of $100 \mathrm{~mA} \mathrm{~g}^{-1}$, corresponding to an initial Coulombic efficiency of ca. $\sim 80 \%$, superior to the GO reference. Furthermore, the 3D-structured nitrogen doped GO displayed enhanced cycling stability, as it maintained a reversible capacity of up to $300 \mathrm{mAh} \mathrm{g}^{-1}$ at $200 \mathrm{~mA} \mathrm{~g}^{-1}$ after 100 cycles. This was likely ascribed to enhanced diffusion of lithium ions within the graphitic layers by the increased $\mathrm{d}$-spacing obtained by $\mathrm{N}$-based functional group doping.

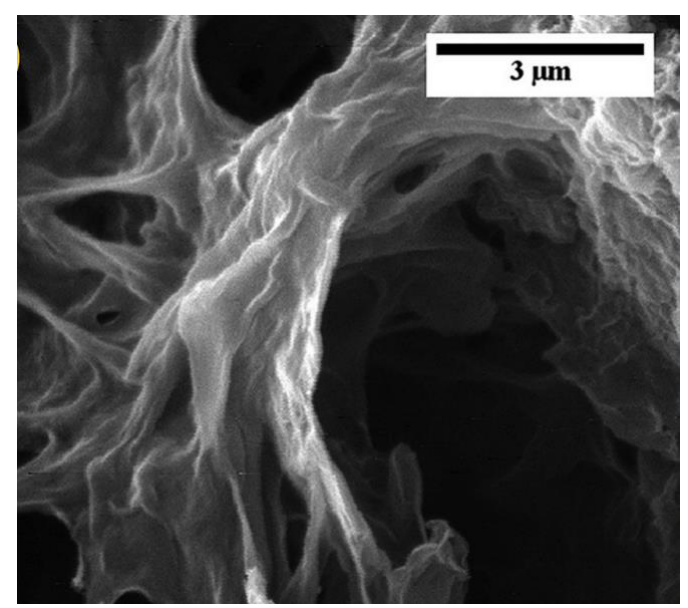

Figure 6. SEM image of 3D-structured nitrogen doped GO as reported by Ershadi et al. [86]. Reproduced, adapted and reprinted with permission from Reference [86]. 
Meng et al. [87] reported a doped rGO, which was obtained by using ionic liquids and GO nanosheets and subsequently heat-treating of the composite. The resulting material exhibited a high specific capacity of $409 \mathrm{mAh} \mathrm{g}^{-1}$ with a Coulombic efficiency approaching $100 \%$ after 50 cycles at a charge/discharge rate of $0.5 \mathrm{C}$, and a specific capacity of $223 \mathrm{mAh} \mathrm{g}^{-1}$ with almost no capacity fading after 1200 cycles at high charge/discharge rate of $10 \mathrm{C}$. This behavior was ascribed to the reduction of superficial oxygen-containing functional groups that limited the side reactions during battery cycling.

\subsection{Tailoring Graphene with Inorganic Nanoparticles for the Production of Nanocomposite Materials}

Another route to introduce defects without compromising the electronic properties of graphene is represented by decoration with nanosized inorganic species [117]. Actually, as reported by Petnikota et al. [118], the presence of nanoparticles onto the graphene surface may be a promising solution to hinder the clustering or electroplating and subsequent dendritic growth of Li metal at the anode of lithium metal batteries.

Among all transition metals, manganese is one of the more widely used. Varghese et al. [88] described a surfactant free single-step hydrothermal method for developing $\mathrm{Mn}_{3} \mathrm{O}_{4}$-decorated graphene. Manganese oxide particles were wrapped into graphene showing a nanosized octahedron structure. This composite showed excellent performance as Li-ion battery anode, with a reversible specific capacity of $474 \mathrm{mAh} \mathrm{g}^{-1}$ at $100 \mathrm{~mA} \mathrm{~g}^{-1}$ upon 200 cycles. Compared with the pristine counterpart, pristine $\mathrm{Mn}_{3} \mathrm{O}_{4} /$ graphene decorated electrode exhibited superior electrochemical properties due to the higher porous graphene matrix that improved electronic conductivity and facilitated a fast lithium ion transport, thus enhanced rate capability. Furthermore, the graphene matrix provided a conductive 3D network for $\mathrm{Mn}_{3} \mathrm{O}_{4}$, while $\mathrm{Mn}_{3} \mathrm{O}_{4}$ nano-octahedrons prevented the restacking of graphene. This synergistic effect was also observed by Wang et al. [89], who improved the $\mathrm{Mn}_{3} \mathrm{O}_{4}$ /graphene composites by tailoring graphene sheets with $\mathrm{Mn}_{3} \mathrm{O}_{4}$ nanotubes. These bidimensional structures improved the specific capacity of the $\mathrm{Mn}_{3} \mathrm{O}_{4} /$ graphene composites as LIB anode up to $770 \mathrm{mAh} \mathrm{g}{ }^{-1}$ after 200 cycles. Furthermore, the anode showed a charge capacity of $233 \mathrm{mAh} \mathrm{g}^{-1}$ after 55 cycles for sodium storage.

Zhou et al. [90] further improved $\mathrm{Mn}_{3} \mathrm{O}_{4} /$ graphene by using a laser scribing method to produce $\mathrm{MnO} / \mathrm{Mn}_{3} \mathrm{O}_{4} /$ nitrogen doped graphene hybrids used as binder-free anode for lithium ion batteries with a high reversible capacity of $992 \mathrm{mAh} \mathrm{g}^{-1}$ at $0.2 \mathrm{~A} \mathrm{~g}^{-1}$ and excellent capacity retention $\left(365 \mathrm{~mA} \mathrm{~g}^{-1}\right.$ delivered at $2.0 \mathrm{Ag}^{-1}$ ), as well as a high cycling stability of up to $699 \mathrm{mAh} \mathrm{g}^{-1}$ after 400 cycles at $0.2 \mathrm{~A} \mathrm{~g}^{-1}$. The authors suggested that the homogeneous surface distribution of $\mathrm{MnO} / \mathrm{Mn}_{3} \mathrm{O}_{4}$ nanoparticles onto nitrogen doped graphene produced a dense architecture that allowed for the excellent electrochemical performances of as-designed framework electrodes. The laser scribing method enabled quick fabrication of graphene-based hybrid frameworks directly anchored onto the current collectors, which can also be easily scaled up, thus holding promising real application prospects. Park et al. [119] simply used graphene as intercalating agent for the realization of free-standing carbon paper coated with $\mathrm{MnO}_{2}$. The resulting electrode was used as anode without any current collector, binder and conductor. This free-standing electrode showed a discharge capacity of $945 \mathrm{mAh} \mathrm{g}^{-1}$ at $100 \mathrm{~mA} \mathrm{~g}^{-1}$ and a high discharge capacity of $545 \mathrm{mAh} \mathrm{g}^{-1}$ at $1000 \mathrm{~mA} \mathrm{~g}^{-1}$ even after 1000 cycles. The authors concluded that the cycling stability was due to the mesoporosity of $\mathrm{MnO}_{2}$ and the intercalation of graphene, which enhanced the kinetics of the redox reaction and mitigated the electrochemical isolation of $\mathrm{MnO}_{2}$ from the carbon nanofibers. Li et al. [120] fabricated a free-standing anode composed of tubular graphene tailored with manganese carbodiimide nanoparticles. These nanoparticles provided abundant active sites for electrochemical reaction and the high conductivity of graphene facilitated the intrinsic electron pathways and efficient ion transport channels. Furthermore, the $\pi-\pi$ orbital interaction between manganese carbodiimide nanoparticles and graphene improved the interfacial charge transport. The LIB anode produced with this methodology showed a high areal capacity of up to $9.8 \mathrm{mAh} \mathrm{cm}^{-2}$ at $0.5 \mathrm{mAcm}^{-2}$, with high capacity retention $\left(3.5 \mathrm{mAh} \mathrm{cm}{ }^{-2}\right.$ delivered at $\left.50 \mathrm{~mA} \mathrm{~cm}^{-2}\right)$ even at a high mass loading of $10 \mathrm{mg} \mathrm{cm}^{-2}$. When coupled in a lithium ion full cell arrangement 
with the $\mathrm{LiCoO}_{2}$ cathode, this anode allowed the attainment of outstanding energy density values of $15 \mathrm{mWh} \mathrm{cm}^{-2}$ and $343 \mathrm{Wh} \mathrm{kg}^{-1}$.

Muhammad et al. [92] decorated with $\mathrm{MnO}_{2}$ nanotubes by adopting a simple sonication technique allowing the integration of the components driven by electrostatic interaction between $\mathrm{GO}$ functional groups and $\mathrm{MnO}_{2}$ nanotubes. As a result, strong chemical bonding was established by virtue of oxygen bridges, such as Mn-O-C linkage due to the hydroxyl/epoxy groups pinning from GO onto the manganese atoms. This integration of graphene oxide was found to be beneficial to reduce the volume expansion as well as the charge transfer resistance and, in addition, to enhance the interfacial properties and structural stability during charge/discharge cycling. Consequently, the resulting anode showed a lithium storage capacity up to $1290 \mathrm{mAh} \mathrm{g}^{-1}$ at $0.1 \mathrm{~A} \mathrm{~g}^{-1}$, with a substantial preservation of the nanotube structure even after 800 cycles. The interaction between manganese and GO surface groups was also used by Weng et al. [121] for the production of anodes based on $\mathrm{Mn}_{3} \mathrm{O}_{4} / \mathrm{rGO}$ with a capacity of $677 \mathrm{mAh} \mathrm{g}^{-1}$ at $123 \mathrm{~mA} \mathrm{~g}^{-1}$, with a retention equal to $85 \%$ after 150 charge/discharge cycles and appreciable rate capability, as for the delivery of $640 \mathrm{mAh} \mathrm{g}^{-1}$ even when using a high current density of $1.2 \mathrm{~A} \mathrm{~g}^{-1}$. The authors explained the good performances by the enhanced lithium ion diffusion coefficient in the composites than in the neat precursors.

Zinc oxide is another widely used transition metal oxide anode in LIBs. Li et al. [91] tailored electrochemical exfoliated graphene with porous carbon-coated polyhedral zinc oxide nanoparticles. As in the case of manganese oxides, graphene prevented the aggregation of $\mathrm{ZnO}$ nanoparticles opening at the same time increased number of channels for lithium-ion diffusion. As an anode material for LIBs, this graphene-based hybrid material showed a reversible capacity of $736 \mathrm{mAh} \mathrm{g}^{-1}$ at $0.1 \mathrm{C}$ after 100 cycles. Yang et al. [122] prepared a graphene coated with $\mathrm{ZnO}$ nanoparticles through the ball milling technique. The resulting LIB anode exhibited an excellent reversible capacity of $720 \mathrm{mAh} \mathrm{g}^{-1}$ at $200 \mathrm{~mA} \mathrm{~g}^{-1}$ and $480 \mathrm{mAh} \mathrm{g}^{-1}$ even at $1600 \mathrm{~mA} \mathrm{~g}^{-1}$. The authors also reported a systematic investigation in lab-scale full cells with commercial cathodes $\left(\mathrm{LiCoO}_{2}, \mathrm{LiNi}_{0.8} \mathrm{Co}_{0.1} \mathrm{Mn}_{0.1} \mathrm{O}_{2}\right)$. Under different pre-lithiation times used to tune the appropriate compensating amount of initial irreversible capacity, the highest performing full cell delivered a reversible capacity around $400 \mathrm{mAh} \mathrm{g}^{-1}$ at $100 \mathrm{~mA} \mathrm{~g}^{-1}$ at an average working potential of about $3.8 \mathrm{~V}$, which resulted in a high energy density of $1478 \mathrm{Wh} \mathrm{kg}^{-1}$. The authors also described the ability of graphene layers to improve both conductivity and mechanical strength by forming a 3D network with $\mathrm{ZnO}$ nanoparticles suppressing their volumetric expansion/contraction effect. Furthermore, the graphene surface cracks and defects produced during ball milling improved the ion-diffusion coefficient and electronic mobility.

Iron oxide has found several applications combined with graphene for the realization of lithium ion battery anodes. Liu et al. [93] combined graphene with iron oxide showing remarkable mitigation of the pulverization of iron-oxide anode upon fast charge/discharge in lithium ion batteries. $\mathrm{j}$ reported a new process based on the polymerization of pyrrole that wrapped the colloidal iron hydroxide nanoparticles onto graphene oxide surface. This composite was further annealed to give carbonized poly (pyrrole) wrapped with $\mathrm{Fe}_{3} \mathrm{O}_{4}$ supported onto graphene. As an anode material, the composite exhibited a highly reversible capacity of $721 \mathrm{mAh} \mathrm{g}^{-1}$ over 320 cycles at a current density of $0.2 \mathrm{Ag}^{-1}$. Even at a high current density of $2 \mathrm{~A} \mathrm{~g}^{-1}$, the anode still delivered a high capacity of $406 \mathrm{mAh} \mathrm{g}^{-1}$. $\mathrm{Li}$ et al. [123] decorated a graphene foam with porous $\mathrm{Fe}_{2} \mathrm{O}_{3} / \mathrm{Fe}_{3} \mathrm{O}_{4}$ deposited onto octahedral carbon for the production of highly conductive composites. This material was prepared by combustion of iron precursors with GO and triethylamine in air atmosphere. During the combustion process, GO flakes were reduced forming a nitrogen doped graphene foam. Meanwhile, iron species were transformed into porous mixed oxides arrayed onto the graphene foam. During this process, the porous structure composed by porous carbon and graphene foam relieved the volume expansion of $\mathrm{Fe}_{2} \mathrm{O}_{3} / \mathrm{Fe}_{3} \mathrm{O}_{4}$ nanoparticles enhancing the electrical conductivity of the resulting nanocomposites. The composites showed a high discharge capacity of $1210 \mathrm{mAh} \mathrm{g}^{-1}$ after 200 cycles and long cycle life. Similarly, Liao et al. [94] produced a $\mathrm{Fe}_{3} \mathrm{O}_{4}$-pillared onto $\mathrm{SiO}_{\mathrm{x}}$ microsphere and wrapped by graphene with a simply ball milling approach, as shown in Figure 7 . The ball milling process led to the formation of 
egg-like $\mathrm{SiO}_{x}$-cored composites possessing a strong capability in accommodating the volume changes of micro-sized $\mathrm{SiO}_{x}$ particles during lithium cycling. The related anode was stable at high-rate, even upon long-term cycling, as demonstrated by the high capacity of $833 \mathrm{mAhg}^{-1}$ delivered at $0.5 \mathrm{~A} \mathrm{~g}^{-1}$ after 500 cycles with $82 \%$ capacity retention.

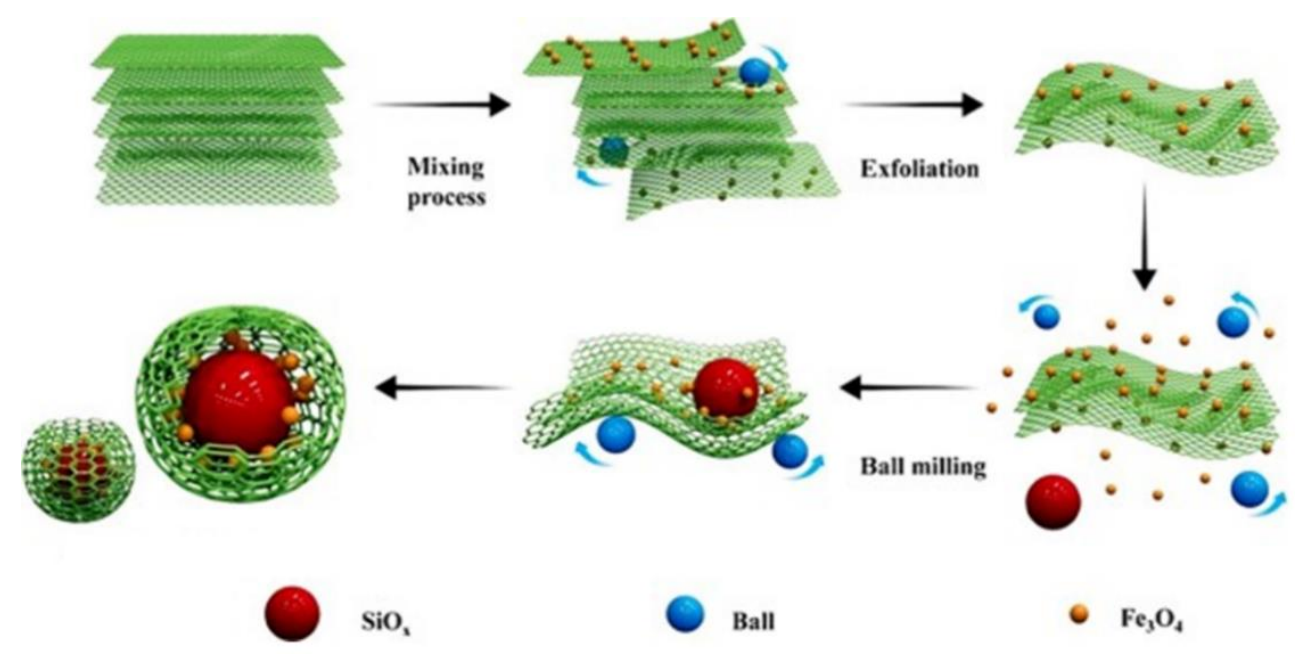

Figure 7. Production scheme of $\mathrm{Fe}_{3} \mathrm{O}_{4}$-pillared onto $\mathrm{SiO}_{\mathrm{x}}$ microspheres and wrapped by graphene. Reproduced, adapted and reprinted with permission from Reference [94].

Chen et al. [124] integrated $\mathrm{Fe}_{2} \mathrm{O}_{3}$ into holey graphene frameworks by using $\mathrm{GO}$ as precursor. Residual defects of GO were first etched by a certain volume of hydrogen peroxide and afterwards multi-dimensionally nanosized $\mathrm{Fe}_{2} \mathrm{O}_{3}$ particles were generated and anchored on the defective graphene layers. This methodology granted an exquisite tuning of $\mathrm{Fe}_{2} \mathrm{O}_{3}$ nanoparticles with highly controllable nanostructures and desirable properties ranging from zero-dimensional quantum dots with an average size of $4.42 \mathrm{~nm}$ to one-dimensional nanorods, and, eventually, to two-dimensional nanosheets. When tested as LIB anodes, these hybrid graphene framework electrodes exhibited excellent cyclic stability at $1 \mathrm{~A} \mathrm{~g}^{-1}$ after 500 cycles up to $806 \mathrm{mAh} \mathrm{g}^{-1}$ for nanorods with a high specific capacity retention even at the current density of $4 \mathrm{~A} \mathrm{~g}^{-1}$. A more traditional synthetic approach was reported by $\mathrm{Gu}$ et al. [125], who tailored graphene sheets with $\mathrm{Fe}_{3} \mathrm{O}_{4}$ nanoparticles via freeze-drying of graphene and iron ion suspension and following solvent thermal synthesis method. Even if the production procedure was rather simple, the authors achieved remarkably high reversible capacity values of $1145 \mathrm{mAhg}^{-1}$ after 120 cycles at $100 \mathrm{mAg}^{-1}$, also coupled with excellent rate capability (650 and $530 \mathrm{mAhg}^{-1}$ delivered at 0.5 and $1 \mathrm{Ag}^{-1}$, respectively). Wu et al. [95] tailored rGO with carbon encapsulated $\mathrm{Fe}_{3} \mathrm{O}_{4}$. The double carbon layer represented by $\mathrm{rGO}$ and coating material not only suppressed the volume expansion of $\mathrm{Fe}_{3} \mathrm{O}_{4}$ during reversible cycling, but also provided an electron transport path for high rate applications. The composite showed a capacity of up to $844 \mathrm{mAhg}^{-1}$ at $0.2 \mathrm{Ag}^{-1}$ even after 300 cycles and high-rate cycling performance of $363 \mathrm{mAhg}^{-1}$ at $4 \mathrm{Ag}^{-1}$ after 300 cycles. Nonetheless, an obvious pseudocapacitance of $77 \%$ of the total capacity was observed at the scan rate of $5 \mathrm{mV} \mathrm{s}^{-1}$ by using cyclic voltammetry. Li et al. [126] used the same approach to realize $\mathrm{rGO}$ coated with monodisperse $\mathrm{Fe}_{3} \mathrm{O}_{4}$ achieving a reversible discharge specific capacity of $1139 \mathrm{mAh} \mathrm{g}^{-1}$ and $85 \%$ capacity retention after 100 cycles at a current density of $400 \mathrm{mAg}^{-1}$. Furthermore, the materials showed a high lithium storage capacity of $665 \mathrm{mAh} \mathrm{g}^{-1}$ even at very high $1000 \mathrm{mAg}^{-1}$ after 200 cycles. Huang et al. [96] firstly synthetized iron phosphide supported on polyhedral carbon in-situ coated with rGO and used as LIB anode, achieving discharge capacity values up to $415 \mathrm{mAhg}^{-1}$ at the current density of $8 \mathrm{Ag}^{-1}$, as well as $950 \mathrm{mAhg}^{-1}$ after 100 cycles at $0.1 \mathrm{Ag}^{-1}$.

Cobalt was also used by Li et al. [97] for the production of cobalt nanoparticles tailored with nitrogen doped graphene. The authors assembled a 2D sandwiched structure of $\mathrm{Co}_{9} \mathrm{~S}_{8}$ supported onto nitrogen doped graphene with a multilayered structure. Electrochemical tests revealed that nanosheets 
possessed a highly reversible capacity up to $1009 \mathrm{mAhg}^{-1}$ at $0.1 \mathrm{Ag}^{-1}$, an excellent capacity retention (422 $\mathrm{mAhg}^{-1}$ provided at $10 \mathrm{Ag}^{-1}$ ), and a long cycle life exceeding 500 cycles. Experimental studies revealed that capacitive storage contributes to the high reversible capacity. Furthermore, the potential of cobalt nanoparticles tailored nitrogen doped graphene anode was tested in a full cell using $\mathrm{LiCoO}_{2}$ as the cathode, exhibiting a highly reversible capacity of $300 \mathrm{mAhg}^{-1}$ cycles at $0.1 \mathrm{Ag}^{-1}$. Wan et al. [98] tailored rGO with a layered mesoporous $\mathrm{CoO}$ achieving a reversible capacity of $1167 \mathrm{mAhg}^{-1}$ at $5 \mathrm{Ag}^{-1}$ with an excellent reversible capacity retention of $76 \%$ over 40 cycles. The authors suggested this behavior to be due to the interphase interaction of nanosheets via Co-O-C bonds leading to enhanced performance. Despite some interesting results and the fact that cobalt is strategically important in many fields, it has been identified as critical raw material (CRM) by EU, as for its concentration of in politically sensitive region of Central Africa, thus its massive use should be better avoided.

$\mathrm{Xu}$ et al. [99] used a nickel salt precursor to grow $\mathrm{Ni} / \mathrm{Ni}_{3} \mathrm{~S}_{2}$ sheets on graphene oxide by a simple two-step solvothermal reaction. The nanoflakes exhibited excellent reversible capacities of 742 and $598 \mathrm{mAhg}^{-1}$ at current densities of $200 \mathrm{mAg}^{-1}$ and $500 \mathrm{mAg}^{-1}$, respectively, which can be actually be well retained after 120 cycles. Additionally, the discharge capacity remained as high as $497 \mathrm{mAg}^{-1}$ even at a very high current density of $1000 \mathrm{mAg}^{-1}$.

Zhang et al. [100] reported on an innovative synthesis of a novel copper oxalate/graphene composite by a facile microwave-assisted hydrothermal process at low temperature. An increased surface area with large porosity is obtained by using $5.42 \mathrm{wt} \%$ of graphene with a uniform distribution of copper species. Excellent electrochemical properties were achieved with a reversible discharge/charge capacity of 1043/1013 mAhg ${ }^{-1}$ after 100 cycles. Additionally, high discharge/charge capacities of 952/949, 719/720, and 535/533 $\mathrm{mAhg}^{-1}$ were provided at increasingly high current densities of $0.5,1.0$, and $2.0 \mathrm{Ag}^{-1}$, respectively.

Several authors tried to combine multimetallic nanoparticles with graphene and related materials for the production of new high performances anodes. As an example, Joshi et al. [127] described the decoration of an electrosprayed graphene film with multicore zinc-iron oxide reaching specific capacity values up to $1601 \mathrm{mAhg}^{-1}$ at $100 \mathrm{mAg}^{-1}$, retaining the original particles morphology. Nickel and cobalt were also used together for tailoring nitrogen-doped graphene reaching specific capacities ranging from $813 \mathrm{mAhg}^{-1}$ upon 200 cycles at $0.2 \mathrm{Ag}^{-1}$ [128] up to $1320 \mathrm{mAhg}^{-1}$ at $120 \mathrm{mAg}^{-1}$ [129], superior rate capability (227 mAh g $\mathrm{m}^{-1}$ at a current density of $3000 \mathrm{~mA} \mathrm{~g}^{-1}$ ) and excellent cycling stability ( $350 \mathrm{mAh} \mathrm{g}^{-1}$ at $1200 \mathrm{~mA} \mathrm{~g}^{-1}$ after 1000 cycles). This work could be extended to develop a variety of advanced electrode materials for next-generation energy storage systems. Furthermore, nickel was combined with tin [130] or copper [131] achieving quite remarkable results. Similarly, cobalt was combined with $\mathrm{ZnO}$ forming nanoclusters, which, coupled with graphene [110], reached specific capacity of $1494 \mathrm{mAhg}^{-1}$ at $0.1 \mathrm{Ag}^{-1}$, with a very good capacity retention even after 1000 cycles $\left(600 \mathrm{mAhg}^{-1}\right.$ at $\left.2.0 \mathrm{Ag}^{-1}\right)$.

Perreault et al. [131], recently developed a straightforward engineering nanostructuring strategy for the preparation of mesoporous $\mathrm{Cu}-\mathrm{Ni}$ oxide-nanocast composites with exfoliated graphene. Actually, an efficient spray drying technique was exploited to prepare a composite in which mesoporous mixed copper/nickel oxide nanoparticles are intimately enwrapped by exfoliated graphene layers. It resulted in $3 \mathrm{D}$ porous microspheres where mesoporous transition metal oxide nanostructures are wrapped by graphene that confines them also forming a continuous conductive network, as shown in Figure 8.

The new proposed method effectively helped in preserving the structure of the electroactive species against drastic volume changes often occurring as a result of reversible cycling, achieving unprecedented electrochemical behavior, such as highly stable reversible specific capacity of $850 / 730 \mathrm{mAhg}^{-1}$ at $1 / 5 \mathrm{mAg}^{-1}$ after 800/1300 cycles, respectively, and higher than $400 \mathrm{mAhg}^{-1}$ at current density as high as $10 \mathrm{mAg}^{-1}$ after $>2000$ cycles, remarkable Coulombic efficiency even upon long-term cycling ( $>3000$ cycles with $>55 \%$ capacity retention). As compared to other existing approaches, the proposed engineering strategy was demonstrated to be facile and efficient; in addition, it is a water-based process, thus environmentally benign and ready to be scaled up at an industrial level. 
Considering data briefly summarized in this paragraph, composites of bimetallic oxides with graphene likely represent a novel and sound idea for new generation of lithium ion battery anode providing enhanced energy density output at high current upon long-term cycling.

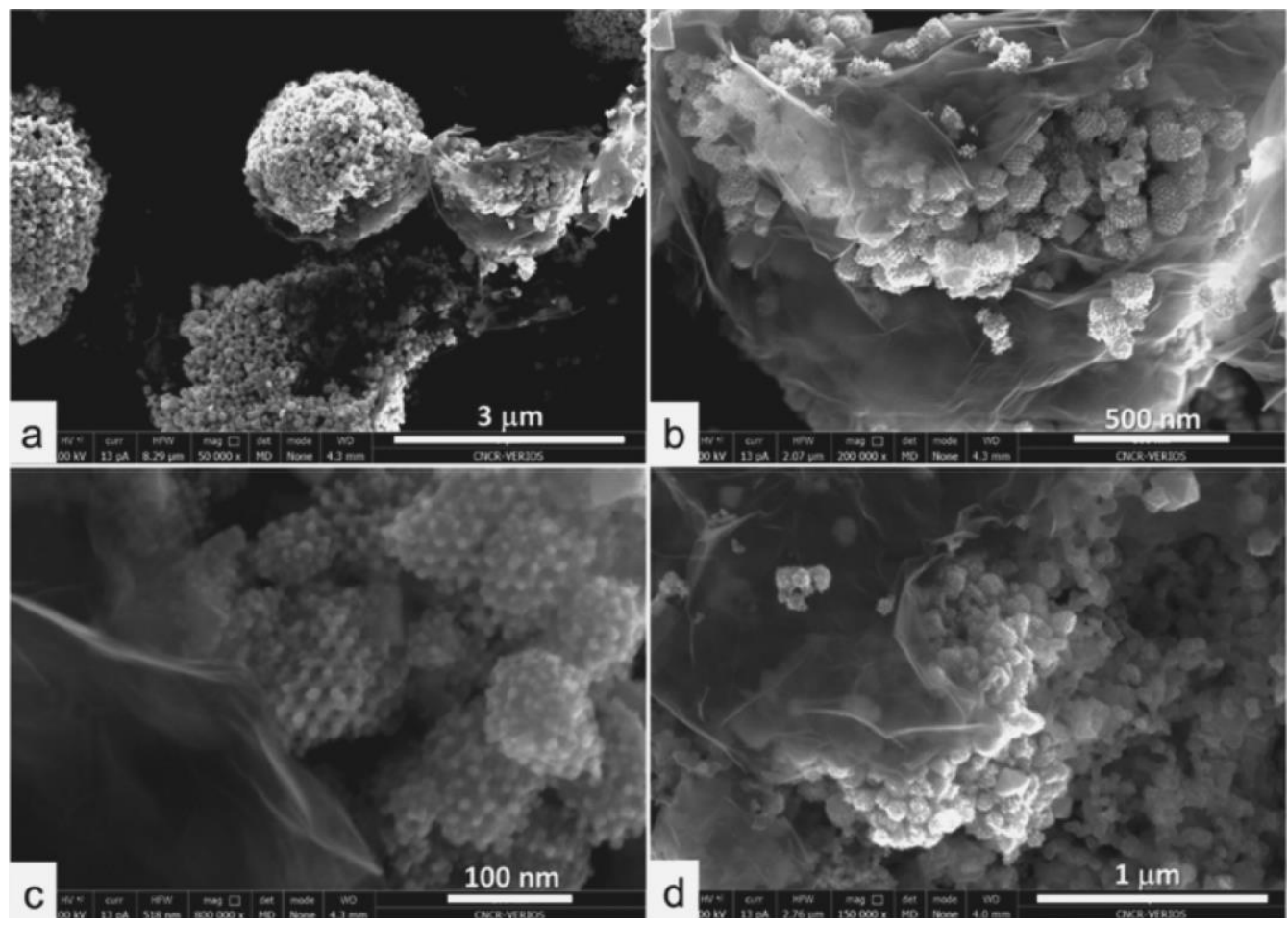

Figure 8. High resolution SEM captions of (a-d) $\mathrm{CuO}-\mathrm{NiO}$ nanoparticles enwrapped within exfoliated graphene nanosheets. Reproduced, adapted and reprinted with permission from Reference [131].

Ma et al. [132] presented a computational study based on DFT modelling of $\mathrm{MoO}_{2} /$ graphene heterostructures showing a high theoretical specific capacity of up to $1411 \mathrm{mAhg}^{-1}$ and small diffusion barriers close to $77 \mathrm{meV}$. The authors suggested the characteristics of these $\mathrm{MoO}_{2} / \mathrm{graphene}$ heterostructures to be compatible with a stable and efficient lithium ion storage performance.

Titanium was widely used coupled with graphene for the production and tailoring of LIB anodes. Li et al. [101] produced a reliable alternative to graphite anodes for LIBs based on graphene decorated with nitrogen doped $\mathrm{TiO}_{2}$ nanotubes mixed with TiN. The resulting composites showed excellent performance, chiefly at low temperature, with highly reversible specific capacity of $211 \mathrm{mAhg}^{-1}$ at $0.1 \mathrm{Ag}^{-1}$ at $-20{ }^{\circ} \mathrm{C}$ ), excellent rate performance up to $1 \mathrm{Ag}^{-1}$ and good cycling stability close to $93 \%$ upon prolonged cycling up to 500 cycles. Jiang et al. [102] tailored graphene with $\mathrm{NaTi}_{2}\left(\mathrm{PO}_{4}\right)_{3} / \mathrm{C}$ by sol-gel technique, which was then applied as a high-performance anode in aqueous lithium-ion battery. The discharge capacity of the resulting full cell assembled in a $\mathrm{NaTi}_{2}\left(\mathrm{PO}_{4}\right)_{3} / \mathrm{C}|| \mathrm{LiMn}_{2} \mathrm{O}_{4}$ configuration reached 108, 86, and $77 \mathrm{mAhg}^{-1}$ at $0.5,10$, and $15 \mathrm{C}$, respectively. Furthermore, the full cell demonstrated an excellent capacity retention of $92 \%$ at $6 \mathrm{C}$ after 1000 cycles. Cheng al. [133] designed a template-free synthesis of mesoporous a $\mathrm{TiO}_{2} /$ graphene aerogel with an unique mesostructured, which facilitated active material wetting by the electrolyte, thus improving the lithium ion diffusion kinetics without noticeably affecting the tap density. When used as LIB anode, the aerogels exhibited a reversible capacity of $663 \mathrm{mAhg}^{-1}$ at a current density of $100 \mathrm{mAg}^{-1}$ after 250 cycles and a reversible capacity of $216 \mathrm{mAh} \mathrm{g}^{-1}$ even at a high current regime of $5 \mathrm{Ag}^{-1}$ after 4000 cycles. Ma et al. [103] synthetized uniformly distributed $\mathrm{TiO}_{2}$ nanorods on $\mathrm{rGO}$ through a facile sol-static self-assembled method followed by an alkali-heat treatment. The resulting flexible rGO nanosheets could serve not only as an electronic conductivity enhancer matrix for the composite material, but also offer large active area for the electrolyte to enhance active material wetting and shorten the paths for lithium ion 
diffusion and electron transfer. As a result, the resulting composites showed interesting electrochemical performance in terms of high cyclic stability at above $354 \mathrm{mAhg}^{-1}$ after 100 cycles at a current density of $0.1 \mathrm{Ag}^{-1}$ and even $205 \mathrm{mAhg}^{-1}$ at high current density of $2 \mathrm{Ag}^{-1}$.

Another transition metal that has been extensively reported as lithium ion battery anode is tin. Zhan et al. [104] decorated nitrogen doped graphene with tin metal nanoparticles, which resulted in a high capacity of $584 \mathrm{mAhg}^{-1}$ at the end of 1000 cycles at $1 \mathrm{Ag}^{-1}$ when tested in lab-scale lithium cell. $\mathrm{SnO}_{2}$ was also widely employed for the decoration of graphene and production of a variety of anode materials with capacity ranging from 569 [134] to $620 \mathrm{mAhg}^{-1}$ [105]. Wu et al. [106] enhanced the synergistic effect of tin and graphene by producing a rGO tailored with $\mathrm{SnO}_{\mathrm{x}}(\mathrm{x}=0,1,2)$ nanoparticles through a facile and low cost synthesis at room temperature mediated by $\mathrm{NaBH}_{4}$. The resulting nanocomposite showed a stable specific capacity values exceeding $830 \mathrm{mAhg}^{-1}$ or $765 \mathrm{mAhg}^{-1}$ after 50 or 100 cycles at $100 \mathrm{mAg}^{-1}$ with capacity retention even at high $1 \mathrm{Ag}^{-1}$. Mei et al. [107] described the production of SnS monolayers combined with nitrogen doped graphene lamellar nanosheets for the realization of an advanced LIB anode. This approach led to a high initial coulombic efficiency of $88.2 \%$, remarkably stable cycling at a high capacity of $790 \mathrm{mAhg}^{-1}$ after 900 cycles at moderate $0.5 \mathrm{C}$ rate.

Due to its specific capacity that is an order of magnitude higher than that of conventional graphite, silicon was one of the first proposed alternatives as anode material in the early stages of LIB development, and it is actually extensively investigated at the research stage as well as already introduced in commercial negative electrodes in small amount combined with graphite [135]. Lin et al. [136] studied graphene coated with both amorphous and nanocrystalline silicon grown by plasma-enhanced deposition. It resulted in the production of a nanocomposite material have the morphology shown in Figure 9. Thanks to the buffering ability of graphene and enhanced electronic conductivity, this material outperformed the pure silicon anode counterpart in terms of delivered specific capacity and, in particular, capacity retention: $79 \%$ retention in specific discharge capacity from 4 th to 200th cycle, by showing as compared to $50 \%$ for pure silicon.

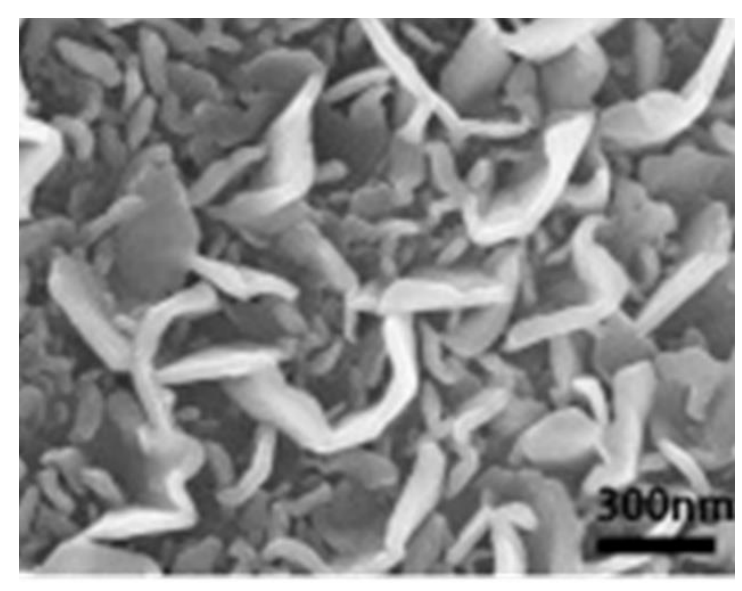

Figure 9. SEM image of graphene coated with both amorphous and nanocrystalline silicon, Reproduced, adapted and reprinted with permission from Reference [136].

Carbon coating was exploited by Hsieh et al. [137] to produce carbon-coated silicon particles bound with few-layered graphene via a liquid exfoliation process. The dense carbon coating on silicon particles was proved as a valuable solution for enhancing the material performances in terms of rate capability, reversible capacity and cycle life. A 3D free-standing anode based nano silicon supported onto soft carbon embedded in graphene was reported by Wang et al. [108]. The authors achieved a superior specific capacity $\left(2600 \mathrm{mAhg}^{-1}\right.$ of specific capacity at a current density of $\left.0.2 \mathrm{Ag}^{-1}\right)$, cycling performance and rate capability and almost no capacity fading after 100 cycles. Another interesting approach was reported by Su and co-workers [109]. Similarly to the approach of Perreault et al. [131], authors produced a hybrid material by a spray-drying method combined with 
a low temperature reduction. As a result, silicon powders with particles having micrometer-sized spherical shape were effectively enwrapped with graphene sheets. This composite delivered a high initial charge capacity of $1298 \mathrm{mAhg}^{-1}$ at $100 \mathrm{mAg}^{-1}$.

Another approach was reported by Han et al. [138] who grew flexible and porous graphene sheets vertically on the surface of the silicon of for accommodating the huge volume changes occurring locally. The authors claimed for a highly reversible capacity of $2696 \mathrm{mAhg}^{-1}$, a long cycling life up to 500 cycles with capacity retention of $80.1 \%$ at $2 \mathrm{Ag}^{-1}$ and an outstanding rate capability (458 $\mathrm{mAhg}^{-1}$ still delivered at $20 \mathrm{Ag}^{-1}$ ). The authors also assembled a laboratory-scale full cell using $\mathrm{LiCoO}_{2}$ as cathode, which showed high gravimetric energy density of $515 \mathrm{Wh} \mathrm{kg}^{-1}$ and volumetric energy density of $1127 \mathrm{Wh} \mathrm{L}^{-1}$.

Cheaper metals such aluminum showed lower performances but an enhanced cost-effectiveness as reported by Gao et al. [111]. The authors synthetized Al-metal organic frameworks (MOF) particles, and then covered them by using graphene to form the composite as shown in Figure 10. It was found that the lithiation/delithiation induced relevant structural modifications in the Al-MOF particles, with a disorder increment. The authors achieved an open channeled structure, thereby enhancing the diffusion and storage of lithium ions. Compared with pure Al-MOF, the Al-MOF/graphene materials demonstrated enhanced the capacity, which increased upon cycling from 60 to $400 \mathrm{mAh} \mathrm{g}^{-1}$ at the constant current density of $100 \mathrm{~mA} \mathrm{~g}^{-1}$.

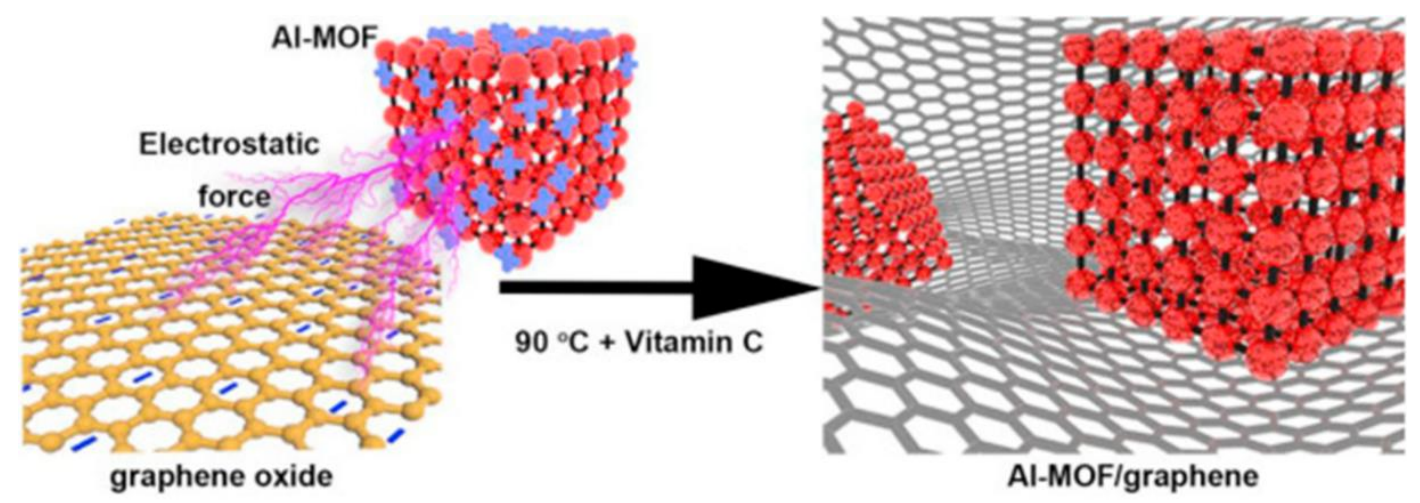

Figure 10. Production scheme of an Al-MOF/graphene composite, Reproduced, adapted and reprinted with permission from Reference [111].

\section{A Brief Perspective on the Future of Graphene and Related Materials for Battery Applications}

Li-ion batteries have been at the forefront of the research for many years and lead to the widespread diffusion and application of new materials and concepts in energy storage creating a bridge between industry and academia. In the near future, the challenge is likely represented by the transition to a near-zero carbon footprint society, which may find in LIBs and post-Li batteries an astonishing tool to improve the consolidation of electric vehicles and large-scale energy storage from renewables. Actually, LIBs have enormous potential to boost the global transition towards a full renewable energy future society Nonetheless, the transition needs to be carried out responsibly. Already in 2010, Prof. Tarascon referred to lithium as "the new gold" [139]. A significant shortage of lithium is unlikely in the near future, but rising prices can be even more problematic, the cost of supply and processing cobalt in positive electrodes being the major contributing factor. In addition, the spreading of LIBs in the last decade rose unavoidable problems due to limited availability and distribution of lithium resources on the Earth's crust [140]. At present, the demand is foreseen to triple in 2025 compared to today's level; moreover, supply, mostly mining, has major environmental impact in terms of significant $\mathrm{CO}_{2}$ emissions and pollution. Thus, it is important to minimize our dependence of cobalt and critical raw materials (CRMs), but it is also fundamental to focus on introducing effective battery recycling procedures, exploit some smart concepts of second-use of exhaust batteries before they 
are discarded and reach the recycling plant, and speed up the transition to new, advanced and safe, high performing materials. Computational studies, at materials level by ab initio and/or multiscale modelling [141] as well as at device level with battery management tools [142,143] are becoming always more important and complementary to drive the experimental research. Academics and industrial researchers are trying to solve this issue following two main routes [144]. The first is represented by the optimization of actual lithium-based materials and technologies. Research and development must focus on new electrode materials and their thorough optimization to push the limits of cost, energy/power density, operational life, and safety. General strategies for performance enhancement may include: (i) innovative syntheses to reduce the size of the active materials to the nanolevel, (ii) doping and functionalization with conductivity enhancers, (iii) development of new nano- composites with tunable particle morphology or coating of active material surface to improve the interfacial properties, (iv) novel, safe solutions for solid-state electrolytes with self-healing features [145]. In this field, the use of high performances materials, such as tailored/functionalized graphene, or even neat graphene, could play a relevant role. The second path is more relevant and it is based on the transition from lithium-based technology to other chemistries based on cheap, more abundant, thus sustainable materials.

Among monovalent cation, sodium [146] and potassium [147] have gained the greatest attention as possible lithium replacement while calcium [148] and magnesium [149] played the main role among the bivalent cations. Those elements are largely available and far cheaper than lithium even if the related energy storage technologies are not up to mark, at present, considering energy density and long term stability [150]. A ground-breaking event could be represented in the near future by the combination of advanced 1D materials with cheap elements, which may allow high energy and power densities, as very recently reported by some preliminary studies [151-164] enlightening the potential bright new future of a modern battery-based society. Hopefully, the best material and/or solution for LIBs is already somewhere in a lab today, just waiting to be unraveled or optimized.

\section{Conclusions}

Graphene, the atomic-scale single layer of carbon atoms bound together in a honeycomb lattice arrangement, might become one of the world's most useful materials. Graphene and related 1D materials have exciting potential and unlimited possibilities for numerous applications; while they are not fully commercially available yet, research and development are intensive both in academia and industry, and will hopefully bring a new era in the energy storage field. The extensively enhanced performance and life cycle advantages when fabricating graphene-based batteries over traditional LIBs are surely worth the huge resource investments of last decade.

As emerged by the results of the scientific studies herein reviewed, we firmly believe that the real breakthroughs in graphene-based batteries will arise from the development of graphene-lithium-ion hybrid chemistries, where graphene and/or related functionalized/doped/modified materials are smartly incorporated into the electrodes of lithium-based cells (e.g., in the anodes of $\mathrm{Li}$-ion batteries, or in combination with sulfur cathodes in Li-S batteries), to allow for high charge and discharge rates, stable long-term cycling and even economical affordability. Actually, there are no opportunities for pure graphene electrodes in LIBs, while graphene is chiefly exploited to enhance many of the benefits already present with traditional materials, also helping in avoiding common materials limitations, eventually leading to increased capacity output or cycle life. Graphene works in electrodes in two general ways, either as a support to enable for improved efficiency, or in the form of composite/hybrid, where its electronic conductivity and well-ordered structure enhance the charge/discharge performance itself. The amount of graphene in the composite electrodes normally varies based on the envisaged application, and generally depends upon the performance requirements in terms of energy/power density and is based upon the existing efficiencies and/or weaknesses of the solid-state precursor material.

Even if such type of technology is still years away from commercialization, pending the amount of issues still to be solved (e.g., cost effectiveness, scalability, sustainability), graphene-based materials and 
related technologies are the most promising candidate for reaching new ground-breaking achievements in the field of lithium ion batteries and, more in general, in next-generation energy storage devices.

Author Contributions: Conceptualization, M.B.; writing-original draft preparation, L.L., G.M., C.G. and M.B.; writing - review and editing, L.L., G.M., C.G. and A.T. All authors have read and agreed to the published version of the manuscript.

Funding: This research received no external funding.

Acknowledgments: The ENABLES project (http://www.enables-project.eu/) has received funding from the European Union's Horizon 2020 research and innovation program, under Grant Agreement no. 730957.

Conflicts of Interest: The authors declare no conflict of interest.

\section{References}

1. Wei, D.; Kivioja, J. Graphene for energy solutions and its industrialization. Nanoscale 2013, 5, 10108-10126. [CrossRef] [PubMed]

2. Lavagna, L.; Marchisio, S.; Merlo, A.; Nisticò, R.; Pavese, M. Polyvinyl butyral-based composites with carbon nanotubes: Efficient dispersion as a key to high mechanical properties. Polym. Compos. 2020. [CrossRef]

3. Kumar, A.; Sharma, K.; Dixit, A.R. A review of the mechanical and thermal properties of graphene and its hybrid polymer nanocomposites for structural applications. J. Mater. Sci. 2019, 54, 5992-6026. [CrossRef]

4. Dadkhah, M.; Saboori, A.; Fino, P. An overview of the recent developments in metal matrix nanocomposites reinforced by graphene. Materials 2019, 12, 2823. [CrossRef] [PubMed]

5. Hidalgo-Manrique, P.; Lei, X.; Xu, R.; Zhou, M.; Kinloch, I.A.; Young, R.J. Copper/graphene composites: A review. J. Mater. Sci. 2019, 54, 12236-12289. [CrossRef]

6. Siochi, E.J. Graphene in the sky and beyond. Nat. Nanotechnol. 2014, 9, 745-747. [CrossRef]

7. Lavagna, L.; Burlon, D.; Nisticò, R.; Brancato, V.; Frazzica, A.; Pavese, M.; Chiavazzo, E. Cementitious composite materials for thermal energy storage applications: A preliminary characterization and theoretical analysis. Sci. Rep. 2020, 10, 12833. [CrossRef]

8. Sood, A.K.; Lund, I.; Puri, Y.R.; Efstathiadis, H.; Haldar, P.; Dhar, N.K.; Lewis, J.; Dubey, M.; Zakar, E.; Wijewarnasuriya, P. Review of Graphene Technology and Its Applications for Electronic Devices; Graphene-New Trends Development: London, UK, 2015.

9. Balandin, A. Toward ubiquitous environmental gas sensors-capitalizing on the promise of graphene. Nat. Mater. 2011, 10, 569-581. [CrossRef] [PubMed]

10. Cui, G.; Bi, Z.; Zhang, R.; Liu, J.; Yu, X.; Li, Z. A comprehensive review on graphene-based anti-corrosive coatings. Chem. Eng. J. 2019, 373, 104-121. [CrossRef]

11. Nine, M.J.; Cole, M.A.; Tran, D.N.; Losic, D. Graphene: A multipurpose material for protective coatings. J. Mater. Chem. A 2015, 3, 12580-12602. [CrossRef]

12. Nag, A.; Mitra, A.; Mukhopadhyay, S.C. Graphene and its sensor-based applications: A review. Sens. Actuators A Phys. 2018, 270, 177-194. [CrossRef]

13. 15 years of graphene electronics. Nat. Electron. 2019, 2, 369. [CrossRef]

14. Heerema, S.J.; Dekker, C. Graphene nanodevices for DNA sequencing. Nat. Nanotechnol. 2016, 11, 127-136. [CrossRef] [PubMed]

15. Liu, J.; Cui, L.; Losic, D. Graphene and graphene oxide as new nanocarriers for drug delivery applications. Acta Biomater. 2013, 9, 9243-9257. [CrossRef]

16. El-Kady, M.F.; Shao, Y.; Kaner, R.B. Graphene for batteries, supercapacitors and beyond. Nat. Rev. Mater. 2016, 1, 16033. [CrossRef]

17. Pistoia, G. Lithium-Ion Batteries; Elsevier: Amsterdam, The Netherladns, 2013.

18. Yoshio, M.; Brodd, R.J.; Kozawa, A. Lithium-Ion Batteries; Springer: New York, NY, USA, 2009; Volume 1.

19. Woody, M.; Arbabzadeh, M.; Lewis, G.M.; Keoleian, G.A.; Stefanopoulou, A. Strategies to limit degradation and maximize Li-ion battery service lifetime-Critical review and guidance for stakeholders. J. Energy Storage 2020, 28, 101231. [CrossRef]

20. Panasonic. NCA103450: Lithium-Ion Batteries. Available online: https://industrial.panasonic.com/ww/ products/batteries/secondary-batteries/lithium-ion/models/NCA103450 (accessed on 17 August 2020). 
21. Panasonic. NCR18650BF: Lithium-Ion Batteries. Available online: https://industrial.panasonic.com/ww/ products/batteries/secondary-batteries/lithium-ion/models/NCR18650BF (accessed on 17 August 2020).

22. Commission, E. Integrated SET-Plan Action 7, “Become Competitive in the Global Battery Sector to Drive Emobility and Stationary Storage Forward". Available online: https://setis.ec.europa.eu/sites/default/files/ set_plan_batteries_implementation_plan.pdf (accessed on 19 August 2020).

23. Lee, C.; Xiaoding, W.; Jeffrey, W.K.; James, H. Measurement of the elastic properties and intrinsic strength of monolayer graphene. Science 2008, 321, 385-388. [CrossRef]

24. Stoller, M.D.; Park, S.; Zhu, Y.; An, J.; Ruoff, R.S. Graphene-based ultracapacitors. Nano Lett. 2008, 8, 3498-3502. [CrossRef]

25. Bolotin, K.I.; Sikes, K.J.; Jiang, Z.; Klima, M.; Fudenberg, G.; Hone, J.; Kim, P.; Stormer, H. Ultrahigh electron mobility in suspended graphene. Solid State Commun. 2008, 146, 351-355. [CrossRef]

26. Rhee, K.Y. Electronic and Thermal Properties of Graphene; Multidisciplinary Digital Publishing Institute: Basel, Switzerland, 2020.

27. Papageorgiou, D.G.; Kinloch, I.A.; Young, R.J. Mechanical properties of graphene and graphene-based nanocomposites. Prog. Mater. Sci. 2017, 90, 75-127. [CrossRef]

28. Zandiatashbar, A.; Lee, G.-H.; An, S.J.; Lee, S.; Mathew, N.; Terrones, M.; Hayashi, T.; Picu, C.R.; Hone, J.; Koratkar, N. Effect of defects on the intrinsic strength and stiffness of graphene. Nat. Commun. 2014, 5, 1-9. [CrossRef] [PubMed]

29. Huang, X. Fabrication and properties of carbon fibers. Materials 2009, 2, 2369-2403. [CrossRef]

30. Liu, Y.; Kumar, S. Recent progress in fabrication, structure, and properties of carbon fibers. Polym. Rev. 2012, 52, 234-258. [CrossRef]

31. Sazali, N.; Salleh, W.; Izwanne, M.N.; Harun, Z.; Kadirgama, K. Precursor selection for carbon membrane fabrication: A review. J. Appl. Membr. Sci. Technol. 2018, 22, 131-144. [CrossRef]

32. Fang, B.; Chang, D.; Xu, Z.; Gao, C. A review on graphene fibers: Expectations, advances, and prospects. Adv. Mater. 2020, 32, 1902664. [CrossRef]

33. Upadhyay, K.K.; Bundaleska, N.; Abrashev, M.; Bundaleski, N.; Teodoro, O.; Fonseca, I.; de Ferro, A.M.; Silva, R.P.; Tatarova, E.; Montemor, M. Free-standing N-Graphene as conductive matrix for $\mathrm{Ni}(\mathrm{OH})_{2}$ based supercapacitive electrodes. Electrochim. Acta 2020, 334, 135592. [CrossRef]

34. Zhang, Z.; Su, X.; Zhu, Y.; Chen, Z.; Fang, Z.; Luo, X. Porous multishelled NiO hollow microspheres encapsulated within three-dimensional graphene as flexible free-standing electrodes for high-performance supercapacitors. Nanoscale 2019, 11, 16071-16079. [CrossRef] [PubMed]

35. Mintmire, J.W.; Dunlap, B.I.; White, C.T. Are fullerene tubules metallic? Phys. Rev. Lett. 1992, 68, 631. [CrossRef]

36. Yan, J.-A.; Ruan, W.; Chou, M. Electron-phonon interactions for optical-phonon modes in few-layer graphene: First-principles calculations. Phys. Rev. B 2009, 79, 115443. [CrossRef]

37. Dresselhaus, M.; Jorio, A.; Saito, R. Characterizing graphene, graphite, and carbon nanotubes by Raman spectroscopy. Annu. Rev. Condens. Matter Phys. 2010, 1, 89-108. [CrossRef]

38. Liu, C.-C.; Walters, A.B.; Vannice, M.A. Measurement of electrical properties of a carbon black. Carbon 1995, 33, 1699-1708. [CrossRef]

39. Abbott's, I.E. Graphene: Exploring carbon flatland. Phys. Today 2007, 60, 35.

40. Ando, T. Exotic electronic and transport properties of graphene. Phys. E Low Dimens. Syst. Nanostruct. 2007, 40, 213-227. [CrossRef]

41. Xu, Z.; Zheng, Q.-S.; Chen, G. Elementary building blocks of graphene-nanoribbon-based electronic devices. Appl. Phys. Lett. 2007, 90, 223115. [CrossRef]

42. Neto, A.C.; Guinea, F.; Peres, N.M.; Novoselov, K.S.; Geim, A.K. The electronic properties of graphene. Rev. Mod. Phys. 2009, 81, 109. [CrossRef]

43. Adelberger, E.; Dvali, G.; Gruzinov, A. Physical Review Letters, 98. Artic. Id 2007, 10402. [CrossRef]

44. Li, X.; Wang, X.; Zhang, L.; Lee, S.; Dai, H. Chemically derived, ultrasmooth graphene nanoribbon semiconductors. Science 2008, 319, 1229. [CrossRef]

45. Araújo, M.P.; Soares, O.; Fernandes, A.; Pereira, M.; Freire, C. Tuning the surface chemistry of graphene flakes: New strategies for selective oxidation. Rsc Adv. 2017, 7, 14290-14301. [CrossRef] 
46. Szabó, T.; Berkesi, O.; Forgó, P.; Josepovits, K.; Sanakis, Y.; Petridis, D.; Dékány, I. Evolution of surface functional groups in a series of progressively oxidized graphite oxides. Chem. Mater. 2006, 18, 2740-2749. [CrossRef]

47. Wang, S.; Sun, H.; Ang, H.-M.; Tadé, M. Adsorptive remediation of environmental pollutants using novel graphene-based nanomaterials. Chem. Eng. J. 2013, 226, 336-347. [CrossRef]

48. Lerf, A.; He, H.; Riedl, T.; Forster, M.; Klinowski, J. 13C and 1H MAS NMR studies of graphite oxide and its chemically modified derivatives. Solid State Ion. 1997, 101, 857-862. [CrossRef]

49. Lee, X.J.; Hiew, B.Y.Z.; Lai, K.C.; Lee, L.Y.; Gan, S.; Thangalazhy-Gopakumar, S.; Rigby, S. Review on graphene and its derivatives: Synthesis methods and potential industrial implementation. J. Taiwan Inst. Chem. Eng. 2019, 98, 163-180. [CrossRef]

50. Li, Z.; Zhang, W.; Wang, H.; Qin, Z. Activated pyrene decorated graphene with enhanced performance for electrochemical energy storage. Chem. Eng. J. 2018, 334, 845-854. [CrossRef]

51. Ambrosi, A.; Chua, C.K.; Bonanni, A.; Pumera, M. Electrochemistry of graphene and related materials. Chem. Rev. 2014, 114, 7150-7188. [CrossRef] [PubMed]

52. Edwards, R.S.; Coleman, K.S. Graphene synthesis: Relationship to applications. Nanoscale 2013, 5, 38-51. [CrossRef] [PubMed]

53. Novoselov, K.S.; Geim, A.K.; Morozov, S.V.; Jiang, D.; Zhang, Y.; Dubonos, S.V.; Grigorieva, I.V.; Firsov, A.A. Electric field effect in atomically thin carbon films. Science 2004, 306, 666-669. [CrossRef]

54. Hernandez, Y.; Nicolosi, V.; Lotya, M.; Blighe, F.M.; Sun, Z.; De, S.; McGovern, I.; Holland, B.; Byrne, M.; Gun'Ko, Y.K. High-yield production of graphene by liquid-phase exfoliation of graphite. Nat. Nanotechnol. 2008, 3, 563-568. [CrossRef] [PubMed]

55. Lotya, M.; Hernandez, Y.; King, P.J.; Smith, R.J.; Nicolosi, V.; Karlsson, L.S.; Blighe, F.M.; De, S.; Wang, Z.; McGovern, I. Liquid phase production of graphene by exfoliation of graphite in surfactant/water solutions. J. Am. Chem. Soc. 2009, 131, 3611-3620. [CrossRef]

56. Lotya, M.; King, P.J.; Khan, U.; De, S.; Coleman, J.N. High-concentration, surfactant-stabilized graphene dispersions. ACS Nano 2010, 4, 3155-3162. [CrossRef]

57. Cote, L.J.; Kim, J.; Tung, V.C.; Luo, J.; Kim, F.; Huang, J. Graphene oxide as surfactant sheets. Pure Appl. Chem. 2010, 83, 95-110. [CrossRef]

58. Vadukumpully, S.; Paul, J.; Valiyaveettil, S. Cationic surfactant mediated exfoliation of graphite into graphene flakes. Carbon 2009, 47, 3288-3294. [CrossRef]

59. Coleman, J.N. Liquid exfoliation of defect-free graphene. Accounts Chem. Res. 2013, 46, 14-22. [CrossRef]

60. Narayan, R.; Kim, S.O. Surfactant mediated liquid phase exfoliation of graphene. Nano Converg. 2015, 2, 20. [CrossRef]

61. Wang, S.; Yi, M.; Shen, Z. The effect of surfactants and their concentration on the liquid exfoliation of graphene. Rsc Adv. 2016, 6, 56705-56710. [CrossRef]

62. Brodie, B.C., XIII. On the atomic weight of graphite. Philos. Trans. R. Soc. Lond. 1859, 149, $249-259$.

63. Staudenmaier, L. Verfahren zur darstellung der graphitsäure. Ber. Dtsch. Chem. Ges. 1898, 31, 1481-1487. [CrossRef]

64. William, S.; Hummers, J.; Offeman, R.E. Preparation of graphitic oxide. J. Am. Chem. Soc. 1958, 80, 1339.

65. Poh, H.L.; Šaněk, F.; Ambrosi, A.; Zhao, G.; Sofer, Z.; Pumera, M. Graphenes prepared by Staudenmaier, Hofmann and Hummers methods with consequent thermal exfoliation exhibit very different electrochemical properties. Nanoscale 2012, 4, 3515-3522. [CrossRef]

66. Chen, J.; Yao, B.; Li, C.; Shi, G. An improved Hummers method for eco-friendly synthesis of graphene oxide. Carbon 2013, 64, 225-229. [CrossRef]

67. Segal, M. Selling graphene by the ton. Nat. Nanotechnol. 2009, 4, 612-614. [CrossRef]

68. Nisticò, R.; Lavagna, L.; Versaci, D.; Ivanchenko, P.; Benzi, P. Chitosan and its char as fillers in cement-base composites: A case study. Bol. Soc. Esp. Cerám. Vidr. 2019.

69. Bartoli, M.; Giorcelli, M.; Jagdale, P.; Rovere, M.; Tagliaferro, A. A review of non-soil biochar applications. Materials 2020, 13, 261. [CrossRef] [PubMed]

70. Tiwari, S.K.; Sahoo, S.; Wang, N.; Huczko, A. Graphene research and their outputs: Status and prospect. J. Sci. Adv. Mater. Devices 2020, 5, 10-29. [CrossRef]

71. Shao, G.; Lu, Y.; Wu, F.; Yang, C.; Zeng, F.; Wu, Q. Graphene oxide: The mechanisms of oxidation and exfoliation. J. Mater. Sci. 2012, 47, 4400-4409. [CrossRef] 
72. Tarascon, J.-M.; Armand, M. Issues and challenges facing rechargeable lithium batteries. In Materials for Sustainable Energy: A Collection of Peer-Reviewed Research and Review Articles from Nature Publishing Group; World Scientific: London, UK, 2011; pp. 171-179.

73. Boehm, H.; Setton, R.; Stumpp, E. Nomenclature and Terminology of Graphite Intercalation Compounds; Pergamon: London, UK, 1986.

74. Scrosati, B. Lithium rocking chair batteries: An old concept? J. Electrochem. Soc. 1992, 139, 2776. [CrossRef]

75. Ohzuku, T.; Iwakoshi, Y.; Sawai, K. Formation of lithium-graphite intercalation compounds in nonaqueous electrolytes and their application as a negative electrode for a lithium ion (shuttlecock) cell. J. Electrochem. Soc. 1993, 140, 2490. [CrossRef]

76. YongJian, W.U.; RenHeng, T.; WenChao, L.I.; Ying, W.; Ling, H.; LiuZhang, O. A high-quality aqueous graphene conductive slurry applied in anode of lithium-ion batteries. J. Alloy. Compd. 2020, 830, 154575. [CrossRef]

77. Zhong, M.; Yan, J.; Wu, H.; Shen, W.; Zhang, J.; Yu, C.; Li, L.; Hao, Q.; Gao, F.; Tian, Y.; et al. Multilayer graphene spheres generated from anthracite and semi-coke as anode materials for lithium-ion batteries. Fuel Process. Technol. 2020, 198, 106241. [CrossRef]

78. Wang, J.; Liu, Y.; Cheng, M.; Zhao, H.; Wang, J.; Zhao, Z.; Duan, X.; Wang, C.; Wang, J. Hierarchical porous carbon-graphene-based Lithium-Sulfur batteries. Electrochim. Acta 2019, 318, 161-168. [CrossRef]

79. Lu, L.; De Hosson, J.T.M.; Pei, Y. Three-dimensional micron-porous graphene foams for lightweight current collectors of lithium-sulfur batteries. Carbon 2019, 144, 713-723. [CrossRef]

80. Xing, B.; Zeng, H.; Huang, G.; Zhang, C.; Yuan, R.; Cao, Y.; Chen, Z.; Yu, J. Porous graphene prepared from anthracite as high performance anode materials for lithium-ion battery applications. J. Alloy. Compd. 2019, 779, 202-211. [CrossRef]

81. Zhou, Y.-Q.; Dong, X.-L.; Li, W.-C.; Hao, G.-P.; Yan, D.; Lu, A.-H. Millimeter-sized few-layer graphene sheets with aligned channels for fast lithium-ion charging kinetics. J. Energy Chem. 2020, 55, 62-69. [CrossRef]

82. Li, R.; Huang, J.; Ren, J.; Cao, L.; Li, J.; Li, W.; Lu, G.; Yu, A. A sandwich-like porous hard carbon/graphene hybrid derived from rapeseed shuck for high-performance lithium-ion batteries. J. Alloy. Compd. 2020, 818, 152849. [CrossRef]

83. Zhang, Y.; Zhang, K.; Jia, K.; Liu, G.; Zhang, Y.; Liu, W.; Li, K.; Zhang, B.; Wang, P. Facile synthesis 2D hierarchical structure of ultrahigh nitrogen-doped porous carbon graphene nanosheets as high-efficiency lithium-ion battery anodes. Mater. Chem. Phys. 2020, 251, 123043. [CrossRef]

84. Wan, H.; Hu, X. New strategy to prepare nitrogen self-doped graphene nanosheets by magnesiothermic reduction and its application in lithium ion batteries. Int. J. Hydrog. Energy 2019, 44, 24369-24376. [CrossRef]

85. Javadian, S.; Atashzar, S.M.; Gharibi, H.; Vafaee, M. Phosphorene and graphene flakes under the effect of external electric field as an anode material for high-performance lithium-ion batteries: A first-principles study. Comput. Mater. Sci. 2019, 165, 144-153. [CrossRef]

86. Ershadi, M.; Javanbakht, M.; Mozaffari, S.A.; Brandell, D.; Lee, M.-T.; Zahiri, B. Facile stitching of graphene oxide nanosheets with ethylenediamine as three dimensional anode material for lithium-ion battery. J. Alloy. Compd. 2020, 818, 152912. [CrossRef]

87. Meng, Y.; Liu, X.; Xiao, M.; Hu, Q.; Li, Y.; Li, R.; Ke, X.; Ren, G.; Zhu, F. Reduced graphene oxide@nitrogen doped carbon with enhanced electrochemical performance in lithium ion batteries. Electrochim. Acta 2019, 309, 228-233. [CrossRef]

88. Varghese, S.P.; Babu, B.; Prasannachandran, R.; Antony, R.; Shaijumon, M.M. Enhanced electrochemical properties of $\mathrm{Mn}_{3} \mathrm{O}_{4}$ /graphene nanocomposite as efficient anode material for lithium ion batteries. J. Alloy. Compd. 2019, 780, 588-596. [CrossRef]

89. Wang, B.; Li, F.; Wang, X.; Wang, G.; Wang, H.; Bai, J. $\mathrm{Mn}_{3} \mathrm{O}_{4}$ nanotubes encapsulated by porous graphene sheets with enhanced electrochemical properties for lithium/sodium-ion batteries. Chem. Eng. J. 2019, 364, 57-69. [CrossRef]

90. Zhou, C.; Zhang, K.; Hong, M.; Yang, Y.; Hu, N.; Su, Y.; Zhang, L.; Zhang, Y. Laser-induced $\mathrm{MnO} / \mathrm{Mn}_{3} \mathrm{O}_{4} / \mathrm{N}$-doped-graphene hybrid as binder-free anodes for lithium ion batteries. Chem. Eng. J. 2020, 385, 123720. [CrossRef]

91. Li, R.; Yue, W.; Chen, X. Fabrication of porous carbon-coated ZnO nanoparticles on electrochemical exfoliated graphene as an anode material for lithium-ion batteries. J. Alloy. Compd. 2019, 784, 800-806. [CrossRef] 
92. Muhammad, N.; Yasin, G.; Li, A.; Chen, Y.; Saleem, H.M.; Liu, R.; Li, D.; Sun, Y.; Zheng, S.; Chen, X.; et al. Volumetric buffering of manganese dioxide nanotubes by employing 'as is' graphene oxide: An approach towards stable metal oxide anode material in lithium-ion batteries. J. Alloy. Compd. 2020, 842, 155803. [CrossRef]

93. Liu, Y.; Miao, X.; Zhang, X.; Chen, S.; Chen, Y.; Cheng, J.; Wang, W.; Zhang, Y. Targeted interfacial anchoring and wrapping of $\mathrm{Fe}_{3} \mathrm{O}_{4}$ nanoparticles onto graphene by PPy-derived-carbon for stable lithium-ion battery anodes. Mater. Res. Bull. 2019, 111, 170-176. [CrossRef]

94. Liao, $\mathrm{C}$; $\mathrm{Wu}, \mathrm{S}$. Pseudocapacitance behavior on $\mathrm{Fe}_{3} \mathrm{O}_{4}$-pillared $\mathrm{SiO}_{\mathrm{x}}$ microsphere wrapped by graphene as high performance anodes for lithium-ion batteries. Chem. Eng. J. 2019, 355, 805-814. [CrossRef]

95. Wu, Q.; Jiang, R.; Liu, H. Carbon layer encapsulated $\mathrm{Fe}_{3} \mathrm{O}_{4} @$ Reduced graphene oxide lithium battery anodes with long cycle performance. Ceram. Int. 2020, 46, 12732-12739. [CrossRef]

96. Huang, Y.; Yu, R.; Mao, G.; Yu, W.; Ding, Z.; Cao, Y.; Zheng, J.; Chu, D.; Tong, H. Unique FeP@C with polyhedral structure in-situ coated with reduced graphene oxide as an anode material for lithium ion batteries. J. Alloy. Compd. 2020, 841, 155670. [CrossRef]

97. Li, N.; Sun, L.; Wang, K.; Xu, S.; Zhang, J.; Guo, X.; Liu, X. Sandwiched N-carbon@Co9S8@Graphene nanosheets as high capacity anode for both half and full lithium-ion batteries. J. Energy Chem. 2020, 51, 62-71. [CrossRef]

98. Wan, B.; Guo, J.; Lai, W.-H.; Wang, Y.-X.; Liu, M.; Liu, H.-K.; Wang, J.-Z.; Chou, S.-L.; Dou, S.-X. Layered mesoporous $\mathrm{CoO} /$ reduced graphene oxide with strong interfacial coupling as a high-performance anode for lithium-ion batteries. J. Alloy. Compd. 2020, 843, 156050. [CrossRef]

99. Xu, J.-L.; Liu, L.; Sun, Y.-H.; Yan, W.-J.; Wang, Z.-R.; Sun, Q. Ni-doped $\mathrm{Ni}_{3} \mathrm{~S}_{2}$ nanoflake intertexture grown on graphene oxide as sheet-like anode for high-performance lithium-ion batteries. J. Alloy. Compd. 2020, 835, 155418. [CrossRef]

100. Zhang, C.; Zheng, B.; Song, Z.; Shi, S.; Mao, H. Microwave-assisted synthesis of a novel $\mathrm{CuC}_{2} \mathrm{O}_{4} \cdot \mathrm{xH}_{2} \mathrm{O} / \mathrm{Graphene}$ composite as anode material for lithium ion batteries. Ceram. Int. 2020, 46, 1018-1025. [CrossRef]

101. Li, J.; Li, Y.; Lan, Q.; Yang, Z.; Lv, X.-J. Multiple phase N-doped $\mathrm{TiO}_{2}$ nanotubes/TiN/graphene nanocomposites for high rate lithium ion batteries at low temperature. J. Power Sources 2019, 423, 166-173. [CrossRef]

102. Jiang, Z.; Li, Y.; Zhu, J.; Li, B.; Li, C.; Wang, L.; Meng, W.; He, Z.; Dai, L. Synthesis and performance of a graphene decorated $\mathrm{NaTi}_{2}\left(\mathrm{PO}_{4}\right)_{3} / \mathrm{C}$ anode for aqueous lithium-ion batteries. J. Alloy. Compd. 2019, 791, 176-183. [CrossRef]

103. Cheng, L.; Qiao, D.; Zhao, P.; He, Y.; Sun, W.; Yu, H.; Jiao, Z. Template-free synthesis of mesoporous succulents-like $\mathrm{TiO}_{2}$ /graphene aerogel composites for lithium-ion batteries. Electrochim. Acta 2019, 300, 417-425. [CrossRef]

104. Ma, Y.; Li, Y.; Li, D.; Liu, Y.; Zhang, J. Uniformly distributed $\mathrm{TiO}_{2}$ nanorods on reduced graphene oxide composites as anode material for high rate lithium ion batteries. J. Alloy. Compd. 2019, 771, 885-891. [CrossRef]

105. Zhan, L.; Zhou, X.; Luo, J.; Ning, X. Ion assisted anchoring Sn nanoparticles on nitrogen-doped graphene as an anode for lithium ion batteries. Int. J. Hydrog. Energy 2019, 44, 24913-24921. [CrossRef]

106. Choi, J.; Myung, Y.; Gu, M.G.; Kim, S.-K. Nanohybrid electrodes of porous hollow $\mathrm{SnO}_{2}$ and graphene aerogel for lithium ion battery anodes. J. Ind. Eng. Chem. 2019, 71, 345-350. [CrossRef]

107. Wu, Y.-Z.; Brahma, S.; Weng, S.-C.; Chang, C.-C.; Huang, J.-L. Reduced graphene oxide (RGO)-SnOx $(\mathrm{x}=0,1,2)$ nanocomposite as high performance anode material for lithium-ion batteries. J. Alloy. Compd. 2020, 818, 152889. [CrossRef]

108. Mei, S.; An, W.; Fu, J.; Guo, W.; Feng, X.; Li, X.; Gao, B.; Zhang, X.; Huo, K.; Chu, P.K. Hierarchical micro-flowers self-assembled from SnS monolayers and nitrogen-doped graphene lamellar nanosheets as advanced anode for lithium-ion battery. Electrochim. Acta 2020, 331, 135292. [CrossRef]

109. Wang, F.; Hu, Z.; Mao, L.; Mao, J. Nano-silicon @ soft carbon embedded in graphene scaffold: High-performance 3D free-standing anode for lithium-ion batteries. J. Power Sources 2020, 450, 227692. [CrossRef]

110. Su, M.; Liu, S.; Tao, L.; Tang, Y.; Dou, A.; Lv, J.; Liu, Y. Silicon@graphene composite prepared by spray-drying method as anode for lithium ion batteries. J. Electroanal. Chem. 2019, 844, 86-90. [CrossRef]

111. Yan, Z.; Sun, Z.; Yue, K.; Li, A.; Qian, L. CoO/ZnO nanoclusters immobilized on N-doped 3 D reduced graphene oxide for enhancing lithium storage capacity. J. Alloy. Compd. 2020, 836, 155443. [CrossRef] 
112. Gao, C.; Wang, P.; Wang, Z.; Kær, S.K.; Zhang, Y.; Yue, Y. The disordering-enhanced performances of the Al-MOF/graphene composite anodes for lithium ion batteries. Nano Energy 2019, 65, 104032. [CrossRef]

113. Cui, X.; Zhang, C.; Hao, R.; Hou, Y. Liquid-phase exfoliation, functionalization and applications of graphene. Nanoscale 2011, 3, 2118-2126. [CrossRef]

114. Min, Z.; Wen-Long, W.; Xue-Dong, B. Preparing three-dimensional graphene architectures: Review of recent developments. Chin. Phys. B 2013, 22, 098105.

115. Raghavan, N.; Thangavel, S.; Venugopal, G. A short review on preparation of graphene from waste and bioprecursors. Appl. Mater. Today 2017, 7, 246-254. [CrossRef]

116. Yan, J.; Zhong, M.; Yu, C.; Zhang, J.; Ma, M.; Li, L.; Hao, Q.; Gao, F.; Tian, Y.; Huang, Y.; et al. Multilayer graphene sheets converted directly from anthracite in the presence of molten iron and their applications as anode for lithium ion batteries. Synth. Met. 2020, 263, 116364. [CrossRef]

117. Zhao, Z.; Wang, J.; Cheng, M.; Wu, J.; Zhang, Q.; Liu, X.; Wang, C.; Wang, J.; Li, K.; Wang, J. N-doped porous carbon-graphene cables synthesized for self-standing cathode and anode hosts of Li-S batteries. Electrochim. Acta 2020, 349, 136231. [CrossRef]

118. Li, W.; He, Y.; Wang, L.; Ding, G.; Zhang, Z.-Q.; Lortz, R.W.; Sheng, P.; Wang, N. Electron localization in metal-decorated graphene. Phys. Rev. B 2011, 84, 045431. [CrossRef]

119. Petnikota, S.; Rotte, N.K.; Reddy, M.V.; Srikanth, V.V.S.S.; Chowdari, B.V.R. MgO-Decorated Few-Layered Graphene as an Anode for Li-Ion Batteries. Acs Appl. Mater. Interfaces 2015, 7, 2301-2309. [CrossRef]

120. Park, J.H.; Choi, W.Y.; Lee, S.; Kim, T.-S.; Lee, J.W. Graphene intercalated free-standing carbon paper coated with $\mathrm{MnO}_{2}$ for anode materials of lithium ion batteries. Electrochim. Acta 2020, 348, 136310. [CrossRef]

121. Li, T.; Zhao, W.; Bi, H.; Tang, Y.; Huang, F. Tubular graphene-supported nanoparticulate manganese carbodiimide as a free-standing high-energy and high-rate anode for lithium ion batteries. J. Power Sources 2020, 467, 228252. [CrossRef]

122. Weng, S.-C.; Brahma, S.; Huang, P.-C.; Huang, Y.-C.; Lee, Y.-H.; Chang, C.-C.; Huang, J.-L. Enhanced capacity and significant rate capability of $\mathrm{Mn}_{3} \mathrm{O}_{4}$ /reduced graphene oxide nanocomposite as high performance anode material in lithium-ion batteries. Appl. Surf. Sci. 2020, 505, 144629. [CrossRef]

123. Yang, X.; Qiu, J.; Liu, M.; Ming, H.; Zhang, H.; Li, M.; Zhang, S.; Zhang, T. A surface multiple effect on the $\mathrm{ZnO}$ anode induced by graphene for a high energy lithium-ion full battery. J. Alloy. Compd. 2020, 824, 153945. [CrossRef]

124. Li, Y.; Fu, Y.; Chen, S.; Huang, Z.; Wang, L.; Song, Y. Porous $\mathrm{Fe}_{2} \mathrm{O}_{3} / \mathrm{Fe}_{3} \mathrm{O}_{4} @$ Carbon octahedron arrayed on three-dimensional graphene foam for lithium-ion battery. Compos. Part B Eng. 2019, 171, 130-137. [CrossRef]

125. Chen, C.; Chen, H.W.; Wu, C.Y.; Huang, J.C.; Duh, J.G. Heterostructural modulation of in situ growth of iron oxide/holey graphene framework nanocomposites as excellent electrodes for advanced lithium-ion batteries. Appl. Surf. Sci. 2019, 485, 247-254. [CrossRef]

126. $\mathrm{Gu}, \mathrm{S}$.; $\mathrm{Zhu}, \mathrm{A}$. Graphene nanosheets loaded $\mathrm{Fe}_{3} \mathrm{O}_{4}$ nanoparticles as a promising anode material for lithium ion batteries. J. Alloy. Compd. 2020, 813, 152160. [CrossRef]

127. Li, L.; Wang, H.; Xie, Z.; An, C.; Jiang, G.; Wang, Y. 3D graphene-encapsulated nearly monodisperse $\mathrm{Fe}_{3} \mathrm{O}_{4}$ nanoparticles as high-performance lithium-ion battery anodes. J. Alloy. Compd. 2020, 815, 152337. [CrossRef]

128. Joshi, B.; Samuel, E.; Kim, M.-W.; Kim, K.; Kim, T.-G.; Swihart, M.T.; Yoon, W.Y.; Yoon, S.S. Electrosprayed graphene films decorated with bimetallic (zinc-iron) oxide for lithium-ion battery anodes. J. Alloy. Compd. 2019, 782, 699-708. [CrossRef]

129. Chen, H.; Ma, X.; Shen, P.K. NiCo $\mathrm{S}_{4}$ nanocores in-situ encapsulated in graphene sheets as anode materials for lithium-ion batteries. Chem. Eng. J. 2019, 364, 167-176. [CrossRef]

130. Wang, J.; Zhu, Y.; Zhang, C.; Kong, F.; Tao, S.; Qian, B.; Jiang, X. Bimetal phosphide $\mathrm{Ni}_{1.4} \mathrm{Co}_{0.6} \mathrm{P}$ nanoparticle/carbon@ nitrogen-doped graphene network as high-performance anode materials for lithium-ion batteries. Appl. Surf. Sci. 2019, 485, 413-422. [CrossRef]

131. Chen, J.; Lin, Y.; Chen, Y.; Zheng, Y.; Liu, Y.; Jiang, L.; Feng, Q.; Li, J.; Huang, Z. Three-dimensional hierarchical nanocomposites of $\mathrm{NiSnO}_{3}$ /graphene encapsulated in carbon matrix as long-life anode for lithium-ion batteries. J. Alloy. Compd. 2019, 793, 492-498. [CrossRef]

132. Lefrançois Perreault, L.; Colò, F.; Meligrana, G.; Kim, K.; Fiorilli, S.; Bella, F.; Nair, J.R.; Vitale-Brovarone, C.; Florek, J.; Kleitz, F; et al. Spray-dried mesoporous mixed Cu-Ni Oxide@ graphene nanocomposite microspheres for high power and durable Li-Ion battery anodes. Adv. Energy Mater. 2018, 8, 1802438. [CrossRef] 
133. Ma, J.; Fu, J.; Niu, M.; Quhe, R. $\mathrm{MoO}_{2}$ and graphene heterostructure as promising flexible anodes for lithium-ion batteries. Carbon 2019, 147, 357-363. [CrossRef]

134. Seong, C.-Y.; Jin, X.; Kim, D.K.; Hwang, T.; Piao, Y. Hydrothermal synthesis of uniform tin oxide nanoparticles on reduced activated graphene oxide as anode material for lithium-ion batteries. J. Electroanal. Chem. 2019, 845, 6-12. [CrossRef]

135. Green, M.; Fielder, E.; Scrosati, B.; Wachtler, M.; Moreno, J.S. Structured silicon anodes for lithium battery applications. Electrochem. Solid State Lett. 2003, 6, A75. [CrossRef]

136. Lin, G.; Wang, H.; Zhang, L.; Cheng, Q.; Gong, Z.; Ostrikov, K. Graphene nanowalls conformally coated with amorphous/nanocrystalline $\mathrm{Si}$ as high-performance binder-free nanocomposite anode for lithium-ion batteries. J. Power Sources 2019, 437, 226909. [CrossRef]

137. Hsieh, C.-C.; Liu, W.-R. Carbon-coated Si particles binding with few-layered graphene via a liquid exfoliation process as potential anode materials for lithium-ion batteries. Surf. Coat. Technol. 2020, 387, 125553. [CrossRef]

138. Han, M.; Lin, Z.; Ji, X.; Mu, Y.; Li, J.; Yu, J. Growth of flexible and porous surface layers of vertical graphene sheets for accommodating huge volume change of silicon in lithium-ion battery anodes. Mater. Today Energy 2020, 17, 100445. [CrossRef]

139. Tarascon, J.-M. Is lithium the new gold? Nat. Chem. 2010, 2, 510. [CrossRef]

140. Grosjean, C.; Miranda, P.H.; Perrin, M.; Poggi, P. Assessment of world lithium resources and consequences of their geographic distribution on the expected development of the electric vehicle industry. Renew. Sustain. Energy Rev. 2012, 16, 1735-1744. [CrossRef]

141. Franco, A.A.; Rucci, A.; Brandell, D.; Frayret, C.; Gaberscek, M.; Jankowski, P.; Johansson, P. Boosting Rechargeable Batteries R\&D by Multiscale Modeling: Myth or Reality? Chem. Rev. 2019, 119, 4569-4627. [CrossRef] [PubMed]

142. Wei, Z.; Zhao, D.; He, H.; Cao, W.; Dong, G. A noise-tolerant model parameterization method for lithium-ion battery management system. Appl. Energy 2020, 268, 114932. [CrossRef]

143. Wei, Z.; Zhao, J.; Ji, D.; Tseng, K.J. A multi-timescale estimator for battery state of charge and capacity dual estimation based on an online identified model. Appl. Energy 2017, 204, 1264-1274. [CrossRef]

144. Ponrouch, A.; Palacín, M.R. Post-Li batteries: Promises and challenges. Philos. Trans. R. Soc. A 2019, $377,20180297$. [CrossRef]

145. Nitta, N.; Wu, F.; Lee, J.T.; Yushin, G. Li-ion battery materials: Present and future. Mater. Today 2015, 18, $252-264$. [CrossRef]

146. Delmas, C. Sodium and Sodium-Ion Batteries: 50 Years of Research. Adv. Energy Mater. 2018, 8, 1703137. [CrossRef]

147. Pramudita, J.C.; Sehrawat, D.; Goonetilleke, D.; Sharma, N. An initial review of the status of electrode materials for potassium-ion batteries. Adv. Energy Mater. 2017, 7, 1602911. [CrossRef]

148. Arroyo-de Dompablo, M.E.; Ponrouch, A.; Johansson, P.; Palacín, M.R. Achievements, challenges, and prospects of calcium batteries. Chem. Rev. 2019, 120, 6331-6357. [CrossRef] [PubMed]

149. Mohtadi, R.; Mizuno, F. Magnesium batteries: Current state of the art, issues and future perspectives. Beilstein J. Nanotechnol. 2014, 5, 1291-1311. [CrossRef] [PubMed]

150. Choi, J.W.; Aurbach, D. Promise and reality of post-lithium-ion batteries with high energy densities. Nat. Rev. Mater. 2016, 1, 16013. [CrossRef]

151. Dobrota, A.S.; Pašti, I.A.; Mentus, S.V.; Johansson, B.; Skorodumova, N.V. Altering the reactivity of pristine, $\mathrm{N}$ - and P-doped graphene by strain engineering: A DFT view on energy related aspects. Appl. Surf. Sci. 2020, 514, 145937. [CrossRef]

152. Sun, Y.; Zhu, D.; Liang, Z.; Zhao, Y.; Tian, W.; Ren, X.; Wang, J.; Li, X.; Gao, Y.; Wen, W.; et al. Facile renewable synthesis of nitrogen/oxygen co-doped graphene-like carbon nanocages as general lithium-ion and potassium-ion batteries anode. Carbon 2020, 167, 685-695. [CrossRef]

153. Peng, Q.; Hu, X.; Zeng, T.; Shang, B.; Mao, M.; Jiao, X.; Xi, G. FeSb2S4 anchored on amine-modified graphene towards high-performance anode material for sodium ion batteries. Chem. Eng. J. 2020, 385, 123857. [CrossRef]

154. Dong, X.; Xing, Z.; Zheng, G.; Gao, X.; Hong, H.; Ju, Z.; Zhuang, Q. $\mathrm{MoS}_{2} / \mathrm{N}$-doped graphene aerogles composite anode for high performance sodium/potassium ion batteries. Electrochim. Acta 2020, 339, 135932. [CrossRef] 
155. Dong, Y.; Lin, X.; Wang, D.; Yuan, R.; Zhang, S.; Chen, X.; Bulusheva, L.G.; Okotrub, A.V.; Song, H. Modulating the defects of graphene blocks by ball-milling for ultrahigh gravimetric and volumetric performance and fast sodium storage. Energy Storage Mater. 2020, 30, 287-295. [CrossRef]

156. Li, Y.; Zhao, Y.; Ma, C.; Shi, J.; Zhao, Y. Highly monodispersed graphene $/ \mathrm{SnO}_{2}$ hybrid nanosheets as bifunctional anode materials of Li-ion and Na-ion batteries. J. Alloy. Compd. 2020, 821, 153506. [CrossRef]

157. Zhao, X.; Zhao, Y.; Huang, B.; Yang, Z.; Cai, W.; Sui, J.; Cao, G.; Wang, H.-E. Dual interface coupled molybdenum diselenide for high-performance sodium ion batteries and capacitors. J. Power Sources 2020, 446, 227298. [CrossRef]

158. Dashairya, L.; Saha, P. Antimony Sulphide Nanorods Decorated onto Reduced Graphene Oxide Based Anodes for Sodium-Ion Battery. Mater. Today Proc. 2020, 21, 1899-1904. [CrossRef]

159. Han, J.; Zhang, C.; Kong, D.; He, X.; Xiao, J.; Chen, F.; Tao, Y.; Wan, Y.; Yang, Q.-H. Flowable sulfur template induced fully interconnected pore structures in graphene artefacts towards high volumetric potassium storage. Nano Energy 2020, 72, 104729. [CrossRef]

160. Yamaletdinov, R.D.; Pershin, Y.V. Ultrafast lithium diffusion in bilayer buckled graphene: A comparative study of Li and Na. Scr. Mater. 2020, 178, 139-143. [CrossRef]

161. Chen, C.; Sun, J.; Miao, L.; Yan, Z.; Chen, J. Layered $\mathrm{H}_{0.68} \mathrm{Ti}_{1.83} \mathrm{O}_{4} /$ reduced graphene oxide nanosheets as a novel cathode for rechargeable magnesium batteries. Chem. Commun. 2019, 55, 14578-14581. [CrossRef] [PubMed]

162. Latha, M.; Biswas, S.; Rani, J.V. Application of WS 2-G composite as cathode for rechargeable magnesium batteries. Ionics 2020, 26, 3395-3404. [CrossRef]

163. Niaei, A.H.F.; Hussain, T.; Hankel, M.; Searles, D.J. Hydrogenated defective graphene as an anode material for sodium and calcium ion batteries: A density functional theory study. Carbon 2018, 136, 73-84.

164. Share, K.; Cohn, A.P.; Carter, R.; Rogers, B.; Pint, C.L. Role of nitrogen-doped graphene for improved high-capacity potassium ion battery anodes. ACS Nano 2016, 10, 9738-9744. [CrossRef] [PubMed]

(C) 2020 by the authors. Licensee MDPI, Basel, Switzerland. This article is an open access article distributed under the terms and conditions of the Creative Commons Attribution (CC BY) license (http://creativecommons.org/licenses/by/4.0/). 